Research Article

\title{
Seismic Behavior of RC Bridge Piers Locally Replaced with SFRC-FA Subjected to Torsion Combined with Axial Compression
}

\author{
Jiyang Wang $(\mathbb{D}$, Yongjun Wang, Chenglin Wan, Rongda Chen, Chengbin Liu, \\ and Zhihua Hu
}

College of Civil Engineering and Architecture, Zhejiang University, Hangzhou 310058, China

Correspondence should be addressed to Jiyang Wang; kyotowang@zju.edu.cn

Received 13 September 2020; Revised 10 May 2021; Accepted 20 May 2021; Published 1 June 2021

Academic Editor: Shazim A. Memon

Copyright ( $\odot 2021$ Jiyang Wang et al. This is an open access article distributed under the Creative Commons Attribution License, which permits unrestricted use, distribution, and reproduction in any medium, provided the original work is properly cited.

\begin{abstract}
Under complex seismic forces, the failure characteristics of the plastic hinge region at the bottom of the pier column and the methods improving the ductility have attracted extensive attention. In this study, steel fiber-reinforced concrete with fine aggregate (SFRC-FA) was applied to locally replace the conventional concrete in the potential plastic hinge region at the bottom of the pier column. Five SFRC-FA pier column specimens with different stirrup ratios and different replacement lengths and one conventional reinforced concrete pier column specimen were produced. Using the seismic behavior tests under the combined bending-shear-torsion-axial force, the failure mode, torsional bearing capacity, energy dissipation, and the torsional plastic hinges of the pier columns were investigated. In addition, an equation for calculating the torsional bearing capacity of the new composite pier columns was proposed. The results showed that (1) compared with the reinforced concrete pier column, the plastic hinge was shifted from the bottom of the pier column to the middle of the height of the pier column due to the application of SFRC-FA at the bottom of the pier column, which improved the torsional bearing capacity; (2) the effect of reducing the stirrup ratio of the SFRCFA replacement region on the torsional bearing capacity, cracking mode, energy dissipation, and ductility was not obvious; (3) the accuracy of the new equation based on the space truss model proposed in this article was verified by comparison with the experiments of this study and other researches.
\end{abstract}

\section{Introduction}

The earlier research on bridge piers mainly focused on axial, bending, shear forces, and related seismic performance $[1,2]$. However, reinforced concrete (RC) piers with irregular three-dimensional bridge configurations could result in significant torsional moments in addition to axial, bending, and shear forces during earthquake events. The addition of torsional moment is more likely in skewed or horizontally curved bridges, bridges with unequal spans or column heights, and bridges with outrigger bents [3]. Therefore, many researchers studied the torsional seismic behaviors of RC bridge pier columns and proposed theoretical and numerical hysteretic models [4-8]. Deng et al. [4] found that the length of the torsional plastic hinge increased and the location of the plastic hinge moved upward when columns showed the torsional failure mode. A nonlinear torsional hysteretic model developed by Tirasit and Kawashima [5] was applied to idealize the torsional behavior of bridge piers. Prakash et al. [6] focused on investigating the effect of different cross-sectional shapes, hysteretic torsional and flexural response, damage distribution, and ductility characteristics with respect to various torsion-to-bending moment (T/M) ratios. Moreover, researchers believe that the torsional seismic performance of RC bridge piers needs to be strengthened. Therefore, concrete-filled steel tube (CFST) piers [9-12], fiber-reinforced concrete (FRC) piers [13-16], and other engineered cementitious composite (ECC) piers [17-19] have also been extensively studied.

Against this background, Qiu et al. [20] performed pseudostatic tests on three CFST piers and one RC pier. The test results indicated that the lateral strength, inelastic deformability, and energy dissipation capacity of the CFST specimens were considerably superior to those of the RC 
specimen. Meanwhile, some precise models [21, 22] have also been proposed by Javed et al. to predict the compressive and flexural behaviors of CFST.

FRC and ECC are efficient cement-based composites that can compensate for the drawbacks of quasibrittleness of conventional concrete and has better structural performance than conventional concrete [23-36]. Zhang et al. [24-26] conducted the seismic performance tests of steel fiberreinforced concrete (SFRC) locally reinforced hollow piers at the potential plastic hinges, which showed that the application of SFRC can improve the ductility and bending performance of the piers. Zhang and Dias-da-Costa [27] carried out experiments and finite element analysis to investigate the seismic vulnerability of multispan continuous girder (MSCG) bridges with SFRC piers. This study found that the seismic vulnerability of MSCG bridges with SFRC located only in the plastic region of the piers showed similar behavior when compared with the design adopting SFRC for the whole pier. Mahmood et al. [28] and Fatih et al. [30] conducted experiments and theoretical model studies on the flexural performance of beams with or without steel fibers, which found that steel fibers can be relied upon in plastic hinge regions for strength and RC-SFRC beams can maintain their load-carrying capacity during large plastic rotation and bending moment redistribution. Kim et al. [29] proposed a modified smeared crack truss model, in which steel fibers were modeled as average direct tensile contribution elements, considering directionality and distribution of fibers. The proposed model estimated the shear behavior of the SFRC members well. The test results by $\mathrm{Li}$ et al. [31-35] indicated that the use of ECC materials in the connection plastic region as a replacement of conventional concrete and partial replacement of transverse reinforcement can significantly enhance the joint shear resistance, energy absorption capacity, and cracking response. Therefore, it has been shown that FRCs materials represent a feasible alternative for use in earthquake-resistant structures [33].

However, the above-mentioned research of FRCs materials in the plastic hinge region mainly focused on the seismic performance of structural members subjected to compression-bending-shear (CBS) loads. Moreover, due to the large coarse aggregate, conventional SFRC is likely to cause pouring difficulties in significant reinforcement congestion zone of joints. In order to have the characteristics of superhigh ductility, ECCs materials have the disadvantages of excessive fiber content, many raw materials, high cost, and unsatisfactory workability in the fresh state. Therefore, it is necessary to reduce the coarse aggregate size of SFRC and improve the workability in the fresh state and focus on the seismic behavior and failure mode for strengthening pier columns in the case of compressionbending-shear-torsion.

The aim of this work was to evaluate the effect of the application of steel fiber-reinforced concrete with fine aggregate (SFRC-FA) on the torsional seismic behavior of solid square piers through the comparative analysis of one conventional RC specimen and five SFRC-FA specimens. All the specimens were subjected to combined reversed cyclic lateral torsion and constant axial loading. The reinforcement stirrup ratio, axial compression ratio, and height of the SFRC-FA at the plastic hinge region were considered to better understand their influences on the seismic behavior of bridge piers, including failure pattern, torsional load-rotation angle hysteretic characteristics, envelope curves, torsional bearing capacity, ductility, and energy dissipation. Furthermore, a new equation based on the space truss model was proposed in this article.

\section{Experimental Program and Setup}

Five specimens of RC pier columns locally replaced with SFRC-FA and one specimen of ordinary RC pier column were constructed and tested at Zhejiang University to investigate the influence of SFRC-FA replacement length, stirrup ratio, and axial-torsional loading on the seismic behavior of pier columns.

2.1. Test Specimens. As shown in Figure 1, all the pier column specimens stood approximately $2450 \mathrm{~mm}$ tall and $300 \mathrm{~mm}$ thick. The section dimension of pier columns was $300 \mathrm{~mm} \times 300 \mathrm{~mm}$. To provide fixity at the bottom, a RC foundation block $1000 \mathrm{~mm}$ wide, $400 \mathrm{~mm}$ thick, and $2200 \mathrm{~mm}$ long was built integrally with the body of the pier columns and posttensioned to the floor prior to testing. A $600 \mathrm{~mm}$ wide by $300 \mathrm{~mm}$ loading beam was cast on top of the pier column, and a hydraulic actuator was attached to the specimen at one side of the loading beam. Table 1 shows the different SFRC-FA replacement lengths $\left(L_{r}\right)$ and stirrup ratios $\left(\rho_{s}\right)$ of six specimens. The stirrups applied to the replacement length are spaced at 120,180 , and $240 \mathrm{~mm}$ on the center vertically (Figure 1), resulting in a volumetric stirrup ratio of $\rho_{s}=0.686 \%, 0.432 \%$, and $0.343 \%$, respectively. The pier column specimens were tested in a lateral reverse cyclic manner until severe damage occurred at the potential plastic hinges.

As one of the purposes of this study is to clarify the influence of the SFRC-FA replacement length and the stirrup ratio on the seismic behavior of pier columns under combined action of axial force and torsion, all the specimens were designed to fail under torsional loading, in accordance with the 2008 Guidelines for seismic design of highway bridges [37]. Considering the superstructure dead weight of $620 \mathrm{kN}$, a constant axial compression was applied on the top of the pier column to provide an axial compression ratio of 0.13 .

2.2. Concrete and Reinforcement. Table 2 shows the sectional dimensions and some details of reinforcements. Pier column section contained six D22 bars and two D10 bars, with D8 closed stirrups spaced at $120 \mathrm{~mm}$. The foundation section contained six D16 bars as top and bottom reinforcement, with D8 closed stirrups spaced at $150 \mathrm{~mm}$. The loading beam section contained five D22 bars as top and bottom reinforcement, with D8 closed stirrups spaced at $150 \mathrm{~mm}$. These four types of steel reinforcements were used in the construction of six specimens, as listed in Table 3. Material 


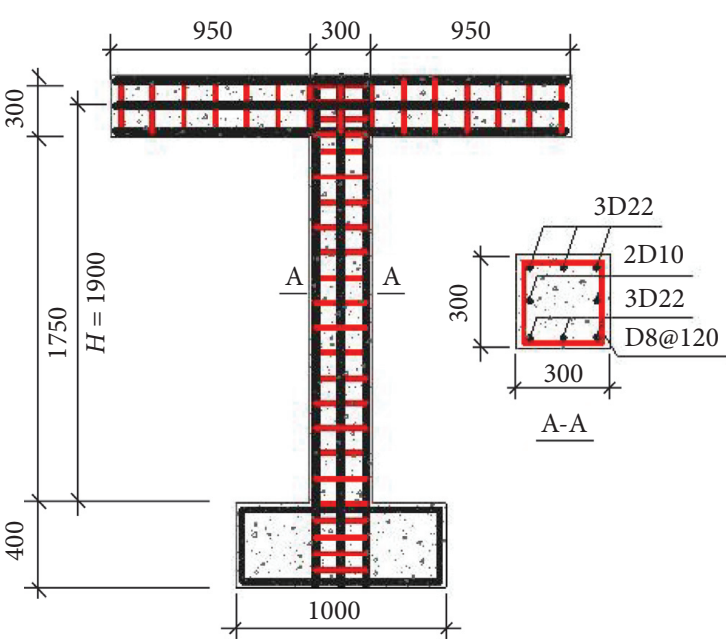

(a)

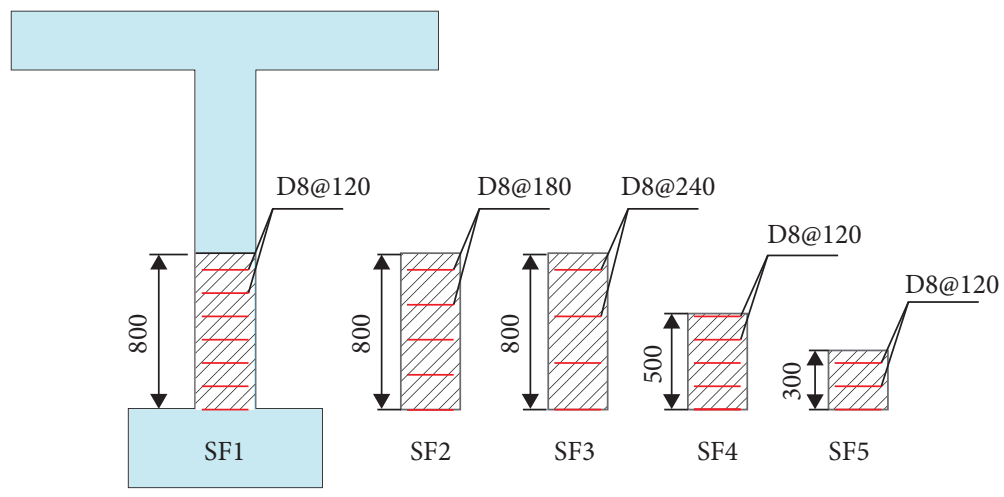

SFRC-FA

Conventional concrete

(c)

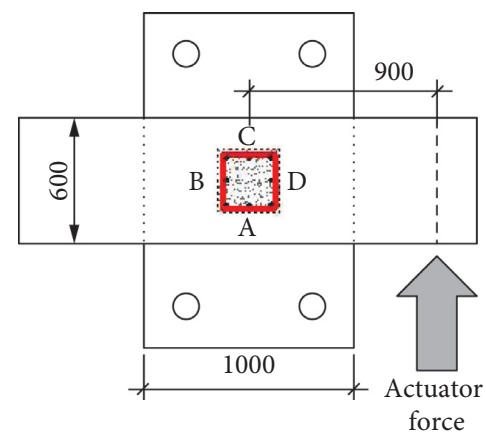

(b)

Figure 1: Specimen configuration. (a) C1 specimen. (b) Top view of specimen. (c) SF1 SF5 specimens.

TABle 1: Parameters of the specimens on replacement region.

\begin{tabular}{lcccccc}
\hline Column & C1 & SF1 & SF2 & SF3 & SF4 & SF5 \\
\hline$L_{r}(\mathrm{~mm})$ & 0 & 800 & 800 & 800 & 500 & 300 \\
$\rho_{s}(\%)$ & 0.686 & 0.686 & 0.432 & 0.343 & 0.686 & 0.686 \\
\hline
\end{tabular}

$L_{r}$ : the locally replaced length using SFRC-FA; $\rho_{s}$ : the stirrup ratio of $L_{r}$.

properties of conventional concrete and SFRC-FA adopted for the specimens are listed in Table 4. The mix design of SFRC-FA used in the experiment and the material indexes of steel fiber are illustrated in Tables 5 and 6, respectively. Among the raw materials of SFRC-FA, the copper-plated steel fibers (Figure 2) with a length of $13 \mathrm{~mm}$ and a diameter of $0.2 \mathrm{~mm}$ were used. According to the previous orthogonal tests of compressive strength, the steel fiber volume content of $2.0 \%$ was optimized [38, 39]. Portland Cement P.II 52.5 conforming to the Chinese Standards GB175-2007 [40] was used. The fine aggregate used was natural river sand passing through a $0.425 \mathrm{~mm}$ sieve whose fineness modulus was 2.5 . The coarse aggregate used was crushed basalt stone with a maximum size of $10 \mathrm{~mm}$. A superplasticizer with waterreducing efficiency of $20 \%$ was used. The measured compressive strength and the bending strength of SFRC-FA were $52.2 \mathrm{MPa}$ and $12.0 \mathrm{MPa}$, respectively. Two kinds of concrete materials of SF1-SF5 specimens were formed by cast-in-situ. The conventional concrete was supplied by a local concrete company, the 28-day measured cube strength of which was $54.5 \mathrm{MPa}$.

2.3. Experimental Setup and Instrumentation. A photograph of experimental setup and the details of the loading system are shown in Figures 3 and 4, respectively. The loading equipment is a $1000 \mathrm{kN}$ MTS actuator with a load range of $\pm 500 \mathrm{kN}$ and a stroke of $\pm 250 \mathrm{~mm}$. The cyclic torsion was generated by controlling the horizontal servo-controlled hydraulic actuator, simulating earthquake forces. All specimens were posttensioned to the rigid floor with bolted connections. In addition, a hydraulic jack was used to exert axial load on the top of pier column through the spherical hinge, which connected the top of the column and the bottom of the jack to maintain an unconstrained boundary condition in the ring direction and constrain the horizontal displacement of the columns. 
TABle 2: Sectional dimension and reinforcement arrangement.

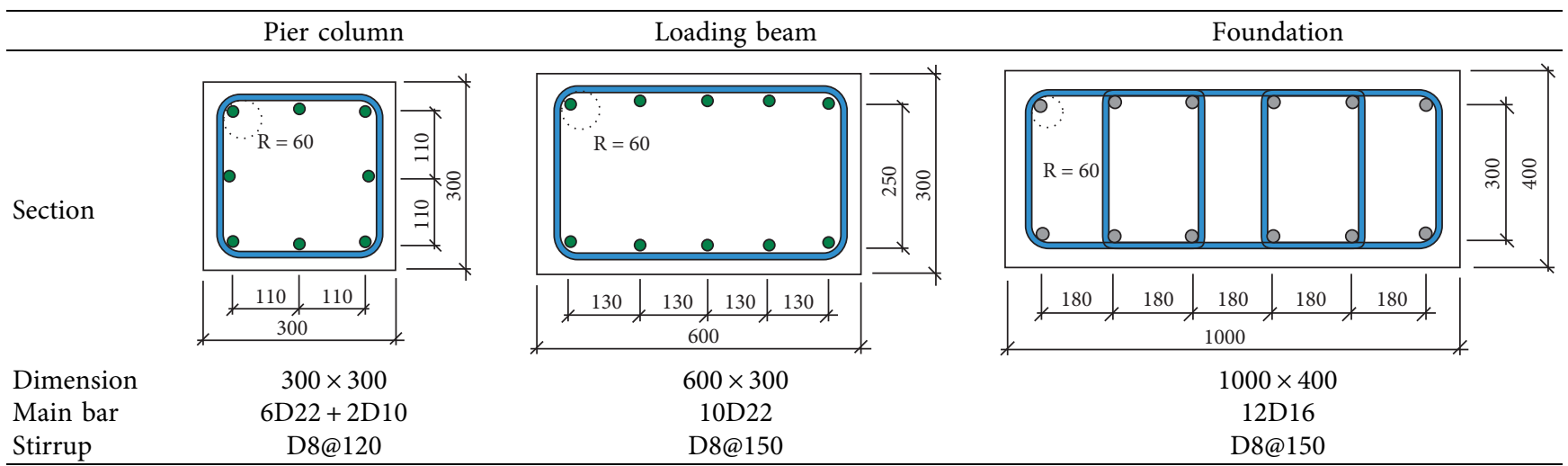

TABLE 3: Reinforcement material properties.

\begin{tabular}{lccc}
\hline Diameter $(\mathrm{mm})$ & Yield strength $(\mathrm{MPa})$ & Ultimate strength $(\mathrm{MPa})$ & Young's modulus $(\mathrm{GPa})$ \\
\hline 8 & 365 & 490 & 180 \\
10 & 571 & 644 & 189 \\
16 & 562 & 631 & 183 \\
22 & 559 & 627 & 194 \\
\hline
\end{tabular}

TABLE 4: Concrete and SFRC-FA material properties.

\begin{tabular}{lccc}
\hline Type & Compressive strength $(\mathrm{MPa})$ & Flexural strength $(\mathrm{MPa})$ & Young's modulus $(\mathrm{GPa})$ \\
\hline Concrete & 54.5 & 6.1 & 34.1 \\
SFRC-FA & 52.2 & 12.0 & 40.8 \\
\hline
\end{tabular}

TABLE 5: Mixture of SFRC-FA.

\begin{tabular}{lcccccc}
\hline $\begin{array}{l}\text { Cement }(\mathrm{kg} / \\
\left.\mathrm{m}^{3}\right)\end{array}$ & $\begin{array}{c}\text { Water }(\mathrm{kg} / \\
\left.\mathrm{m}^{3}\right)\end{array}$ & $\begin{array}{c}\text { Fly ash }(\mathrm{kg} / \\
\left.\mathrm{m}^{3}\right)\end{array}$ & $\begin{array}{c}\text { Aggregate }(\mathrm{kg} / \\
\left.\mathrm{m}^{3}\right)\end{array}$ & $\begin{array}{c}\text { River sand }(\mathrm{kg} / \\
\left.\mathrm{m}^{3}\right)\end{array}$ & $\begin{array}{c}\text { Steel fiber volume ratio } \\
(\%)\end{array}$ & $\begin{array}{c}\text { Superplasticizer }(\mathrm{kg} / \\
\left.\mathrm{m}^{3}\right)\end{array}$ \\
\hline 373 & 242 & 205 & 462 & 993 & 2 & 5 \\
\hline
\end{tabular}

TABLE 6: Indexes of steel fiber.

\begin{tabular}{lcccc}
\hline Diameter $(\mathrm{mm})$ & Length $(\mathrm{mm})$ & Tensile strength $(\mathrm{MPa})$ & Young's modulus $(\mathrm{GPa})$ & Density $\left(\mathrm{g} / \mathrm{cm}^{3}\right)$ \\
\hline 0.2 & 13 & 1500 & 2700 & 7.8 \\
\hline
\end{tabular}

It can be seen in Figure 5 that nine linear variable differential transformers (LVDTs) (named $W_{1} \sim W_{9}$ ) were used for measuring the displacements of each specimen. The displacement transducers, $W_{1} \sim W_{4}$, were installed at the centerline of the loading beam to record the displacement data, which was used to calculate the rotation angle of the pier column $\left(\theta=\left(W_{1}-W_{2}\right) / L\right)$. The remaining horizontal displacement transducers $W_{5} \sim W_{9}$ were installed at the centerline of the pier column to measure the relative displacement at different heights. Figure 6 presented the strain gauges arrangement. Sixteen strain gauges were used to measure strains in transverse stirrups located in the height of $0 \mathrm{~mm}, 180 \mathrm{~mm}, 360 \mathrm{~mm}$, and $1080 \mathrm{~mm}$, respectively. Four strain gauges located at the bottom of pier columns were used to measure the strain changes of the longitudinal bars.
2.4. Loading Protocol. Loading was mainly controlled by measured displacement in terms of the rotation angle $\theta$. The same nominal loading history was used to test all six specimens described herein. The axial compression was first applied to the top of the pier columns to the predetermined axial compression ratio of 0.13 . As shown in Figure 7 , the lateral loading history was divided into three parts: the first part of loading was performed up to predicted cracking load with each single-cycle loading increasing by $7 \mathrm{kN}$; subsequently, displacement was simultaneously applied at a single cycle at every step with a displacement increment of $0.5 \mathrm{~mm}$. After reaching the yielding load, the displacement increment of each step was unified to $1 \mathrm{~mm}$, and three cycles of each step were imposed. In general, $85 \%$ of the ultimate load could be identified as a failure load of the pier columns, and the loading could be terminated [41]. Considering the 


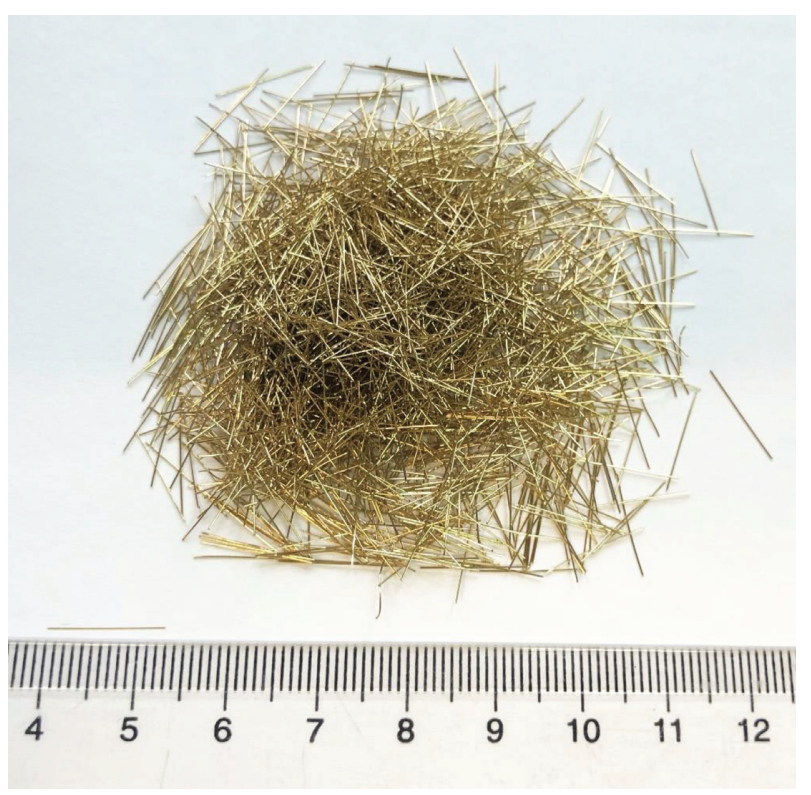

FIGURE 2: Steel fibers.

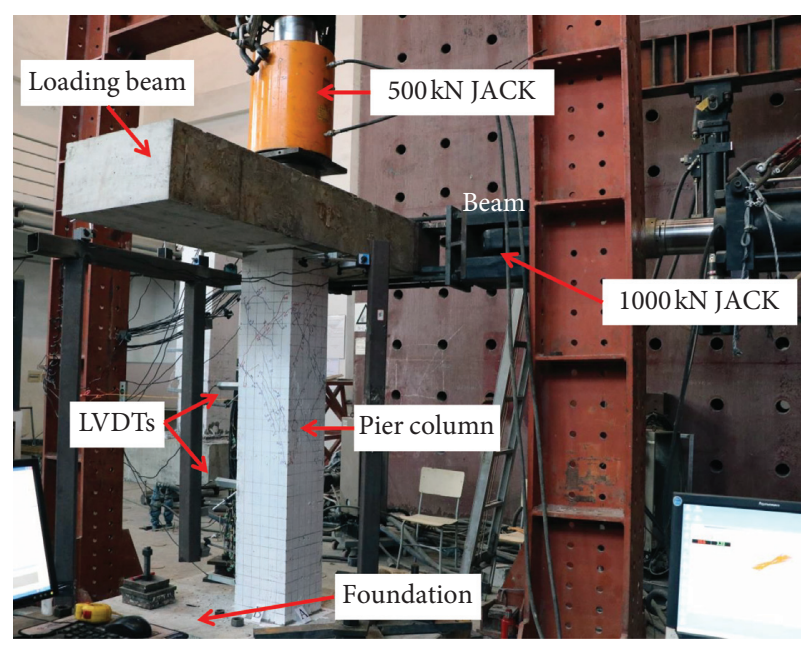

Figure 3: Photograph of the test model installed on the facility.

combined action of axial force, bending moment, and torque, each test continued until the torsional load deteriorated to $70 \% T_{\max }$ or the specimen experienced a significant loss of torsional load. Therefore, instrumentations were used to monitor the applied loads, deformation of the pier column, and strain of the reinforcing bars. And, during the selected loading steps in the tests, the observed damage was recorded with photographs and sketches. The location of cracks, spalling, and any buckled reinforcing bars were documented.

\section{Interpretation of Experimental Results}

3.1. Crack Patterns and Lateral Torsion-Rotation Angle Relations. The crack patterns at the end of tests of six specimens are shown in Figure 8. The positive and negative cracks were marked in red and blue solid lines, respectively. All significant cracks of six specimens were $55-65^{\circ}$ relative to

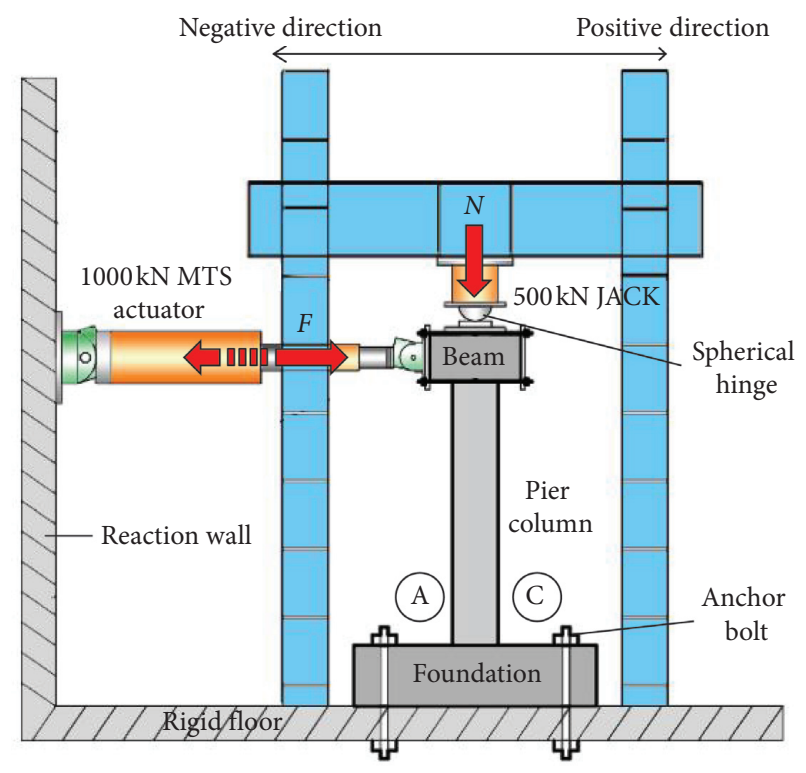

FIGURE 4: Schematic diagram of the test setup.

the pier column cross-section, meaning that the failure mode -was torsion failure. Moreover, no cracks were observed in the SFRC-FA replacement region, and no interfacial cracks or disconnections occurred between conventional concrete and SFRC-FA.

Figures 9-14 show the damage of the six pier column specimens on four surfaces and the hysteresis curves of the torsional moment versus rotation angle. The solid lines show the cracks and the painted parts show the severely damaged area. Torsion and rotation angle at the critical loading stage of six specimens are listed in Table 7. Here, the initial crack point indicated the point corresponding to the torsion and the rotation angle when the first crack occurred in the test. The maximum torsion was directly read from its torsionrotation angle curve, and the maximum value indicates the torsional bearing capacity of the pier column. As shown in Figure 15 [42], the yield rotation angle $\left(\theta_{y}\right)$ was determined when the area enclosed by the torsion-rotation angle curve is equal to that surrounded by bilinear curve when rotation angle ranges from 0 to $\theta_{\mathrm{u}}$ [43]. For the convenience of explanation, we use $T_{\max }$ to indicate the maximum torque of positive load and $-T_{\max }$ to indicate the maximum torque of negative load. The symbols " + " and "-" indicate the difference in the loading direction.

In the case of specimen $\mathrm{C} 1$, the initial cracks occurred at the height of $300 \mathrm{~mm}$ on $\mathrm{A}$ and $\mathrm{D}$ surfaces of the pier column when the load reached $35 \%$ of the maximum negative torque $\left(-T_{\max }\right)$. The positive and negative cracks then gradually extended upward to the height of $1100 \mathrm{~mm}$ and downward to the bottom of the pier column. These cracks eventually met in an area between $200 \mathrm{~mm}$ and $600 \mathrm{~mm}$ in height, and they formed the angle of about $40-60^{\circ}$, as shown in Figure 8. At the final stage of loading, the cover concrete near the bottom of the pier column was crushed and spalled due to a relatively large bendingtorsional moment effect, which was analyzed by the nondimensional bending-torsion ratio [5]. 


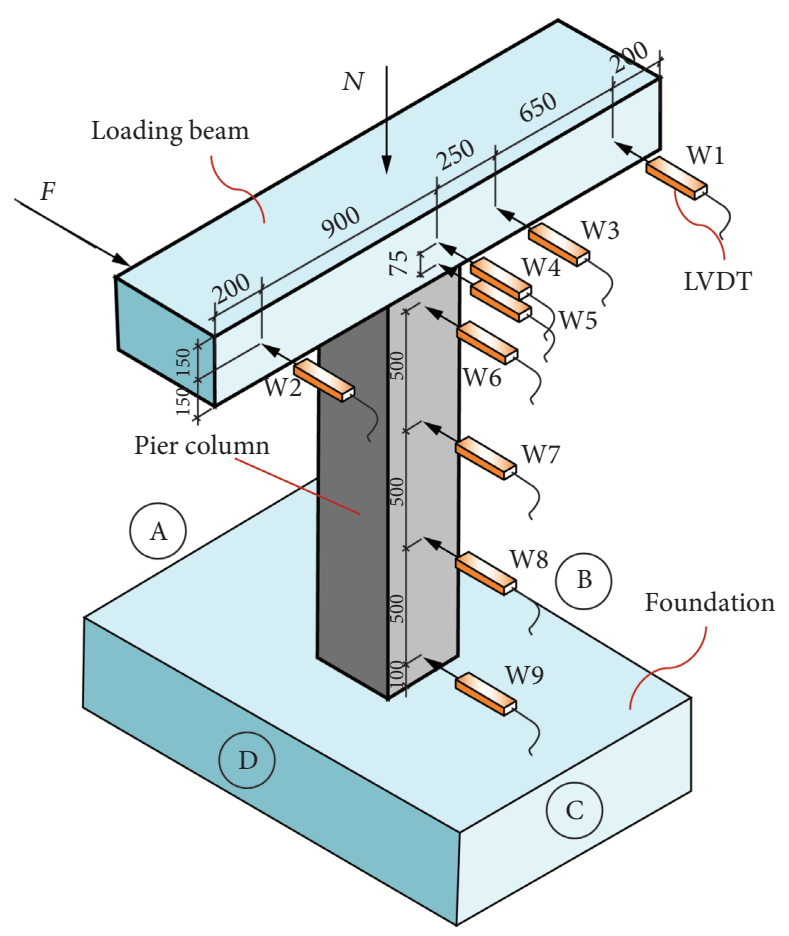

Figure 5: Arrangement of LVDTs.

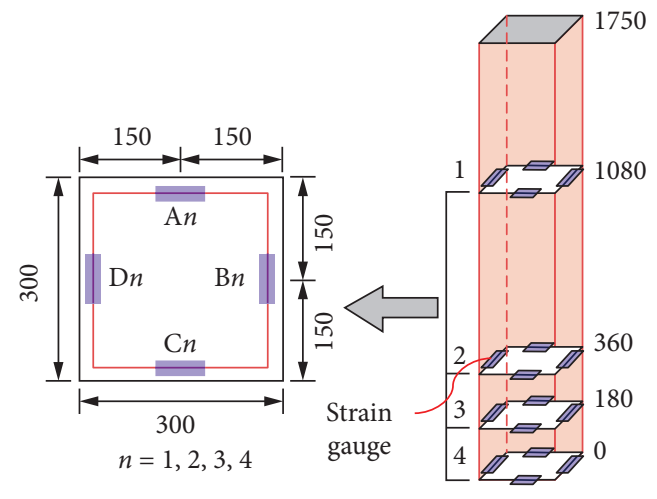

(a)

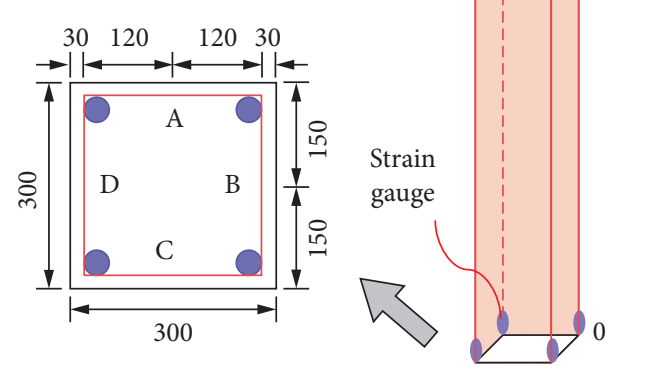

(b)

Figure 6: Locations of strain gauges embedded in stirrups and longitudinal bars (/mm). (a) Stirrups. (b) Longitudinal bars.

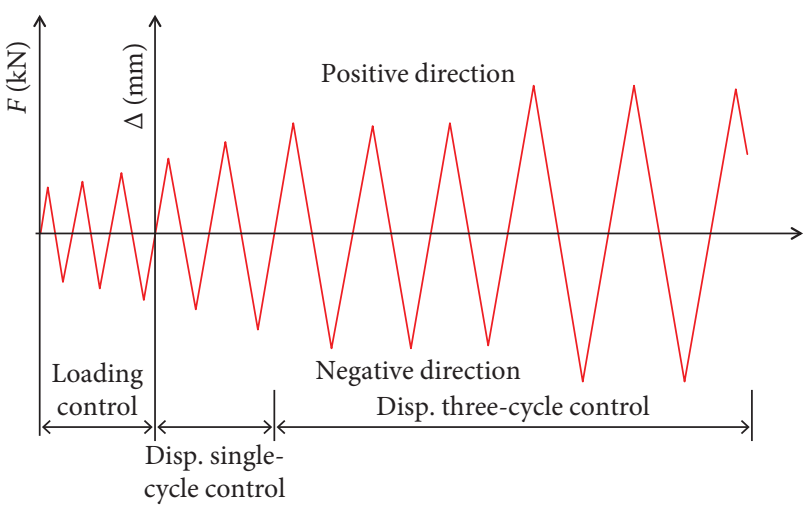

FIGURE 7: Lateral loading history of experimental program.
As shown in Figure 9, the hysteresis curve was approximately linear up to cracking torsion ( $\boldsymbol{\Delta}$ initial crack point); after that, the hysteresis curve became nonlinear as the torsional stiffness decreases moderately. The equivalent positive and negative yielding points were $3.69 \times 10^{-3} \mathrm{rad}$ and $-5.50 \times 10^{-3} \mathrm{rad}$, while the stirrup bar yielded $9.81 \times 10^{-3} \mathrm{rad}$ followed by cover concrete spalling at $300 \mathrm{~mm}$ height of surface C and surface D. As loading continued, the torsion reached the maximum value of $-55.34 \mathrm{kN} \cdot \mathrm{m} \quad\left(-T_{\max }\right)$ at the rotation angle of $-9.33 \times 10^{-3}$ rad followed by a long stage of deterioration. Finally, the torsion deteriorated to $77 \% \times\left(-T_{\max }\right)$ at the rotation angle of $-19.43 \times 10^{-3} \mathrm{rad}$, at which the loading was terminated. The experimental results of specimen $\mathrm{C} 1$ were used as a benchmark for analyzing the seismic performance 

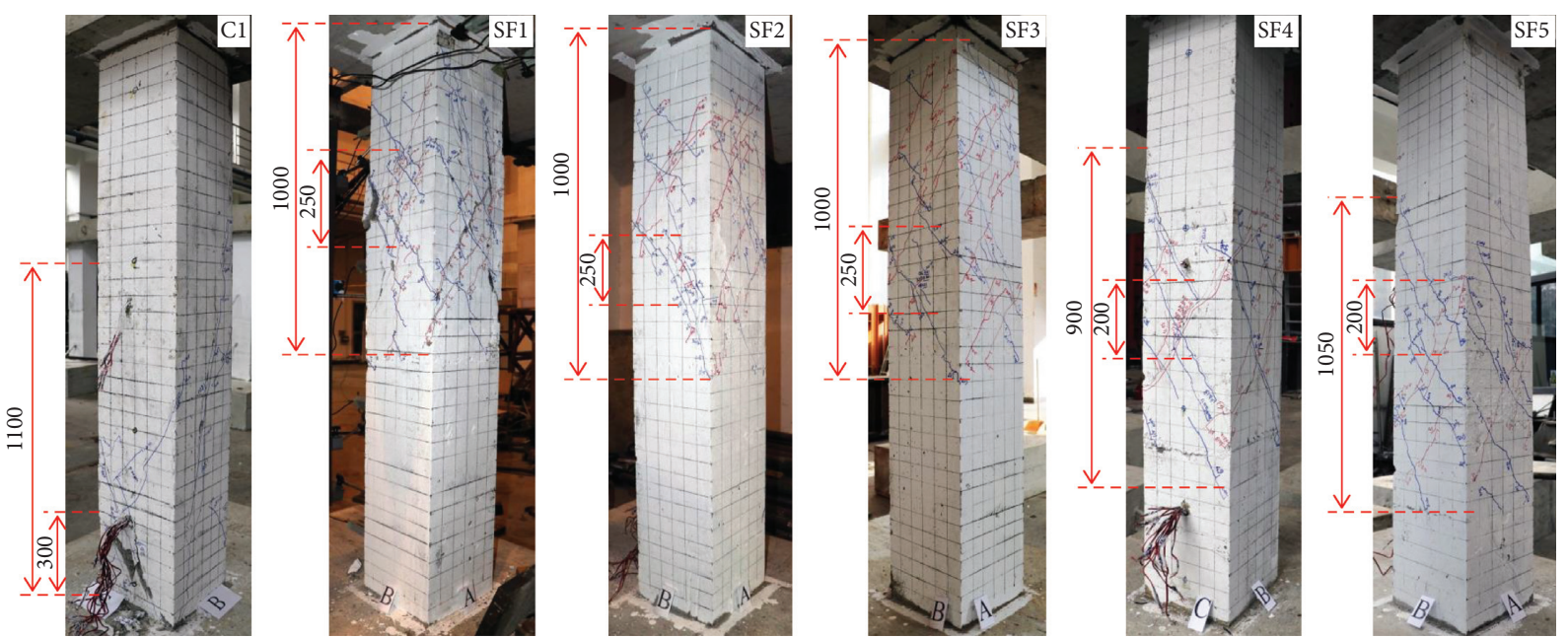

Figure 8: Crack propagation at the end of tests.
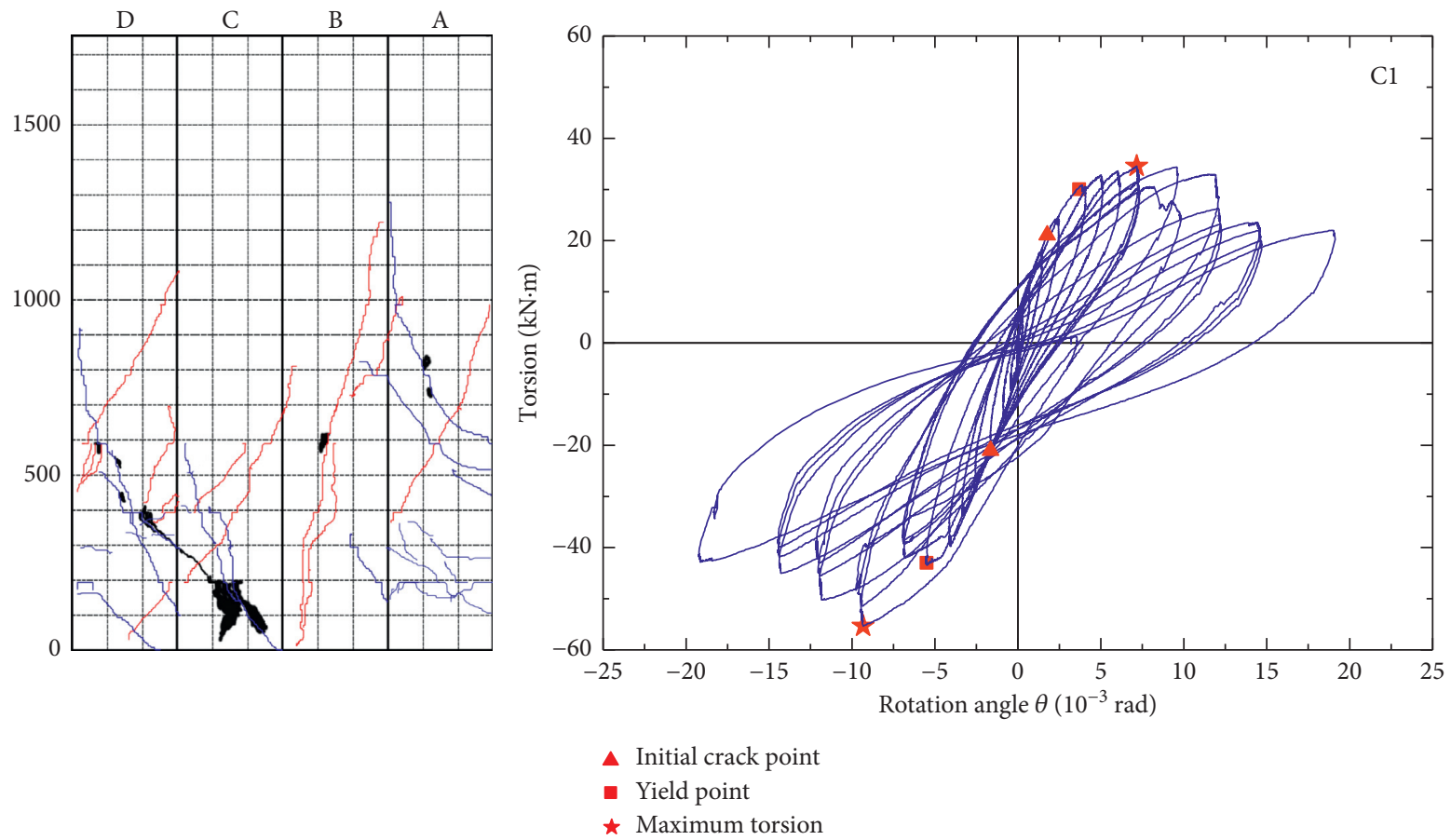

Figure 9: Damage and hysteresis curves of specimen C1.

of other specimens with different SFRC-FA replacement lengths.

In the cases of specimens SF1, SF2, and SF3, the crack morphology and the crack distribution were similar, although the stirrup ratios in the SFRC-FA replacement section were $0.686 \%, 0.432 \%$, and $0.343 \%$, respectively (Figures 10-12). Oblique and spiral cracks occurred in these three pier columns and extended from the height of $800 \mathrm{~mm}$ to the top of the pier columns, while no cracks were observed in the SFRC-FA replacement region at the bottom of the pier column. Although the stirrup ratios of these three specimens were different, few differences in crack propagation and cracked region were found. However, structural performances such as crack patterns, plastic hinge regions, and torsional strength deterioration were different from specimen C1. The hysteresis curve could be regarded as three stages: in the first stage, the curve was almost linear until the peak torsion; in the second stage, the torsion bearing capacity decreased suddenly by about $15 \% T_{\max }$ in a loading cycle; in the third stage, as the rotation angle increases, the torsion bearing capacity decreases slowly, which showed well ductility.

Due to replacement by SFRC-FA at the bottom of the pier column, no cracks observed until the torque of SF1, $\mathrm{SF} 2$, and SF3 reached $39.2 \mathrm{kN} \cdot \mathrm{m},-44.9 \mathrm{kN} \cdot \mathrm{m}$, and $42.5 \mathrm{kN} \cdot \mathrm{m}$, which were $70 \%, 72 \%$, and $74 \%$ of their maximum torsion $\left( \pm T_{\max }\right)$, respectively. Obviously, their cracking torque was much high than that of specimen $\mathrm{C} 1$ 

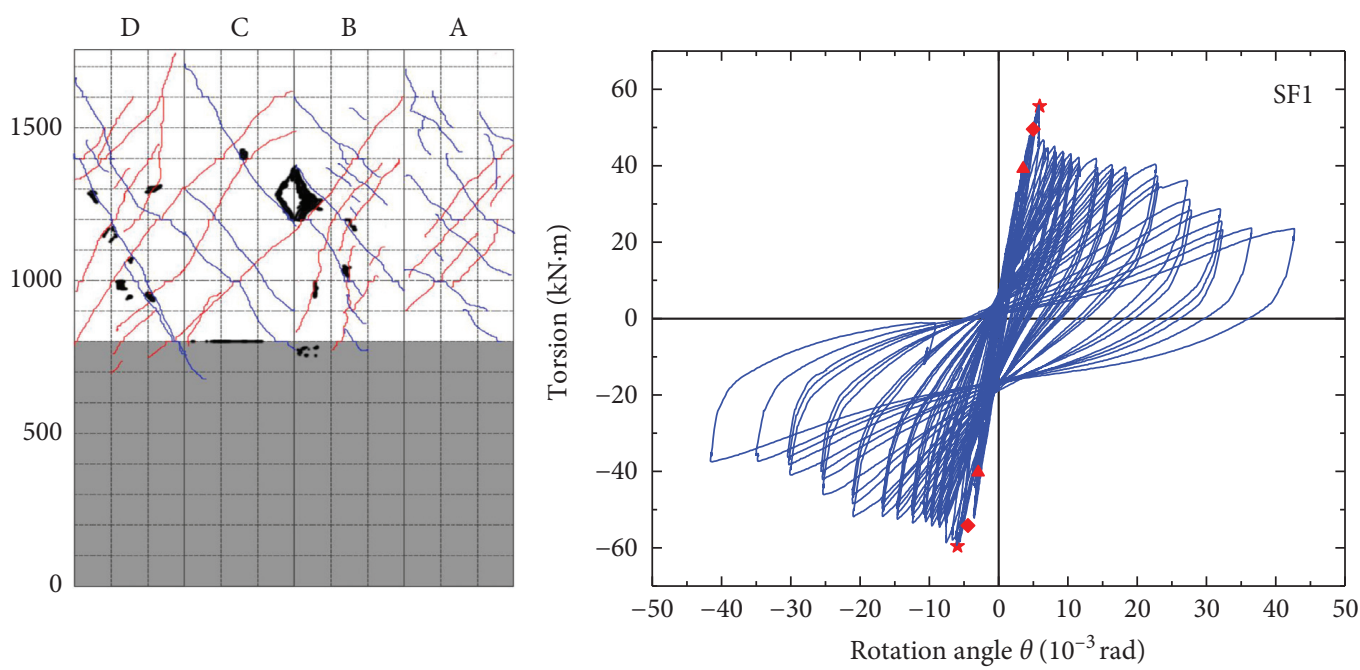

- Initial crack point

- Yield point

$\star$ Maximum torsion

Figure 10: Damage and hysteresis curves of specimen SF1.
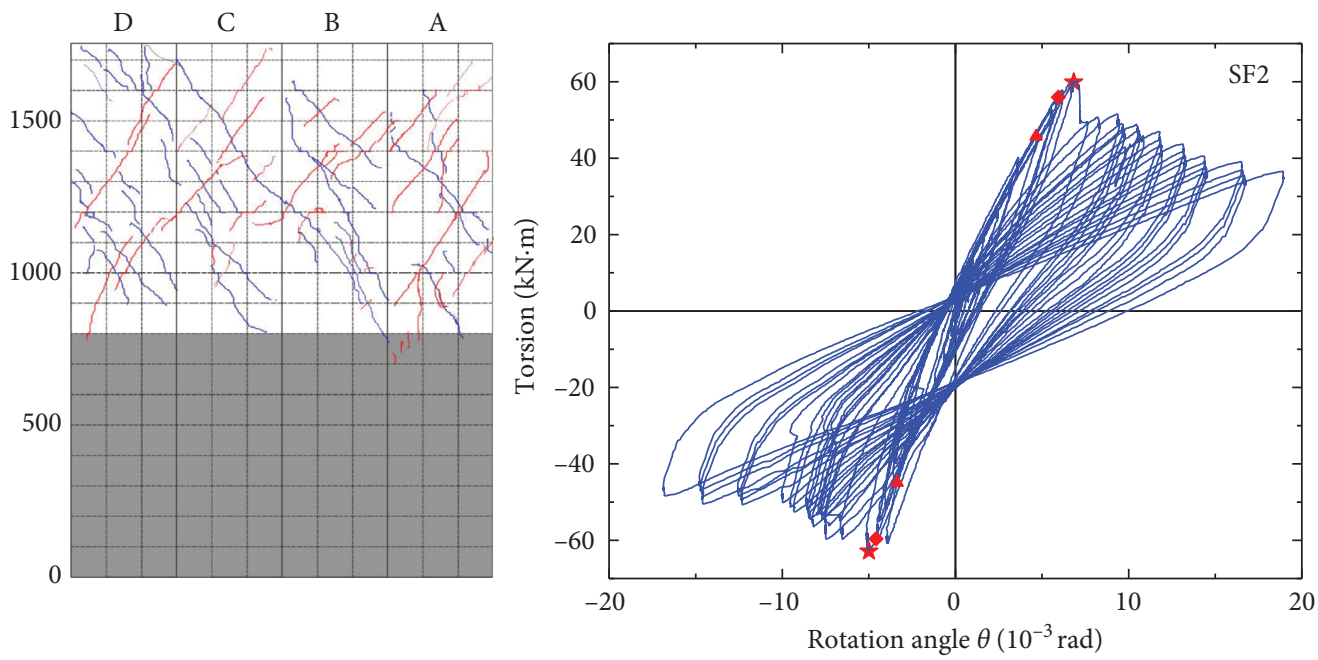

- Initial crack point

- Yield point

$\star$ Maximum torsion

FIGURE 11: Damage and hysteresis curves of specimen SF2.

$\left(-35 \% T_{\max }\right)$. Taking SF1 for example, cracks quickly extended through surfaces $\mathrm{C}$ and $\mathrm{D}$ from the initial one at $1050 \mathrm{~mm}$ height with a 60 -degree angle relative to the horizontal direction. Subsequently, the crack width gradually became larger and the torque of SF1 reached $T_{\max }$ of $55.84 \mathrm{kN} \cdot \mathrm{m}$ at a rotation angle of $5.78 \times 10^{-3} \mathrm{rad}$, which was smaller than the rotation angle of $\mathrm{C} 1$ at the maximum torque. Moreover, the torsional bearing capacity of SF1 decreased suddenly after $T_{\max }$, unlike $\mathrm{C} 1$. After that, as the torsional bearing capacity slowly decreased, the conventional concrete on the upper part of the pier column gradually cracked and spalled, forming a concentrated region of cracks and large rotational deformation near the mid-height of the upper column, which was assumed to be a torsional plastic hinge. As shown in Figure 8, the torsional plastic hinge length of SF1, SF2, and SF3 was about $250 \mathrm{~mm}, 200 \mathrm{~mm}$, and $250 \mathrm{~mm}$, respectively. The stirrups in the torsional plastic hinge region all yielded at a rotation angle level of $42.59 \times 10^{-3} \mathrm{rad}$, while in the SFRC-FA replacement region, neither did the stirrups yield nor did cracks occur on the surface. Although some of the stirrups in the SFRC-FA region yielded in the final failure mode, there were almost no cracks on the four surfaces of the SFRC-FA replacement region, which showed that SFRCFA improved the torsional bearing capacity and deformation capacity of the pier column. 

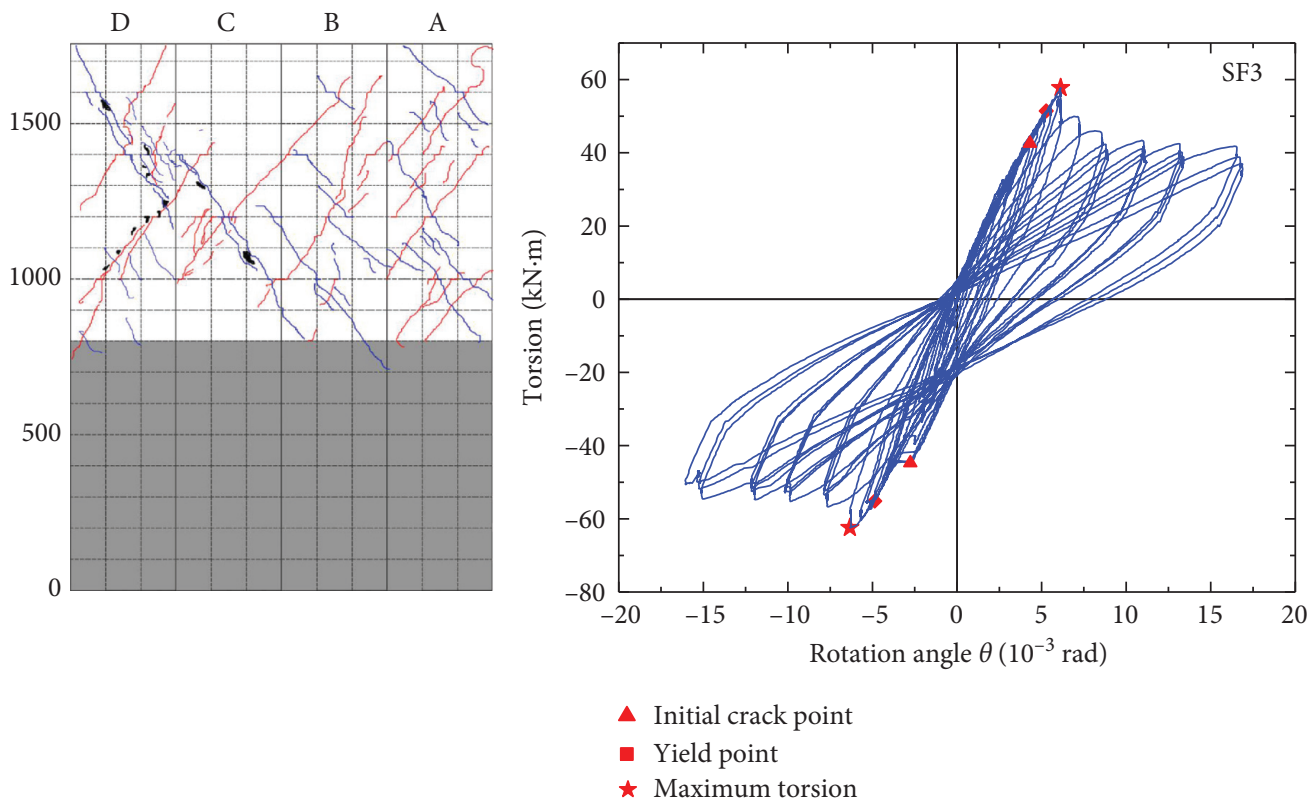

FIGURE 12: Damage and hysteresis curves of specimen SF3.
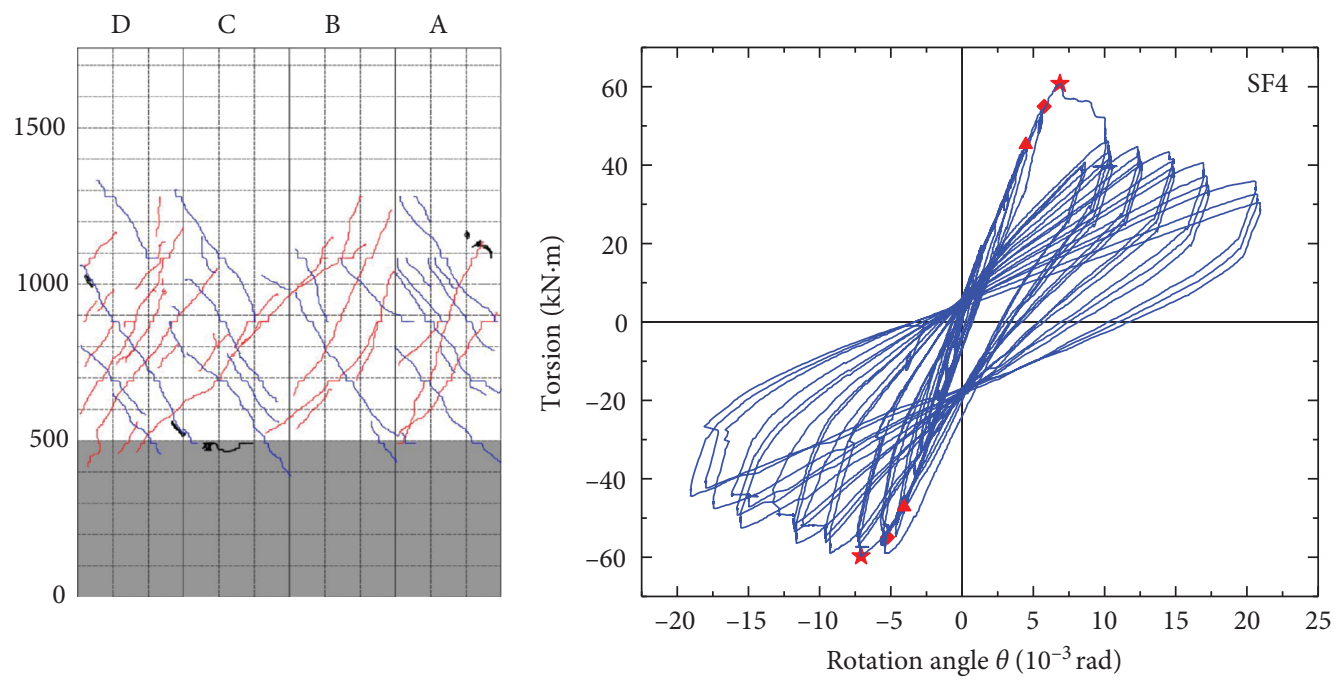

- Initial crack point

- Yield point

$\star$ Maximum torsion

FIGURE 13: Damage and hysteresis curves of specimen SF4.

In the cases of specimens SF4 and SF5, the crack morphology and the crack distribution were similar to those of SF1, SF2, and SF3, as shown in Figures 13 and 14, while the cracked regions moved down relative to the shorter replacement length. The cracked region of SF4 and SF5 concentrated in the height of $500-1350 \mathrm{~mm}$ and 300-1450 mm, respectively. In comparison with $\mathrm{C} 1$, the cracked regions of SF4 and SF5 formed at an upper height, whereas they formed at a lower height compared to SF1-SF3, keeping away from the SFRC-FA replacement region.
For the specimen SF4, when the rotation angle reached $4.47 \times 10^{-3} \mathrm{rad}(45.24 \mathrm{kN} \cdot \mathrm{m})$, the initial diagonal cracks occurred, and they expanded rapidly in the range of $500 \mathrm{~mm}$ to $1000 \mathrm{~mm}$ on all four surfaces. However, when the rotation angle of specimen SF5 reached $3.91 \times 10^{-3} \mathrm{rad}(38.15 \mathrm{kN} \cdot \mathrm{m})$, the initial diagonal cracks occurred on the surface of $\mathrm{C}$ and $\mathrm{D}$, and they expanded rapidly in the range of $300 \mathrm{~mm}$ to $400 \mathrm{~mm}$ height. Both SF4 and SF5 reached the maximum torsional bearing capacity soon after cracks occurred. Afterward, the cracks of SF4 and SF5 expanded at 60 degrees in the range of $450-1300 \mathrm{~mm}$ and $250-1400 \mathrm{~mm}$, respectively. 

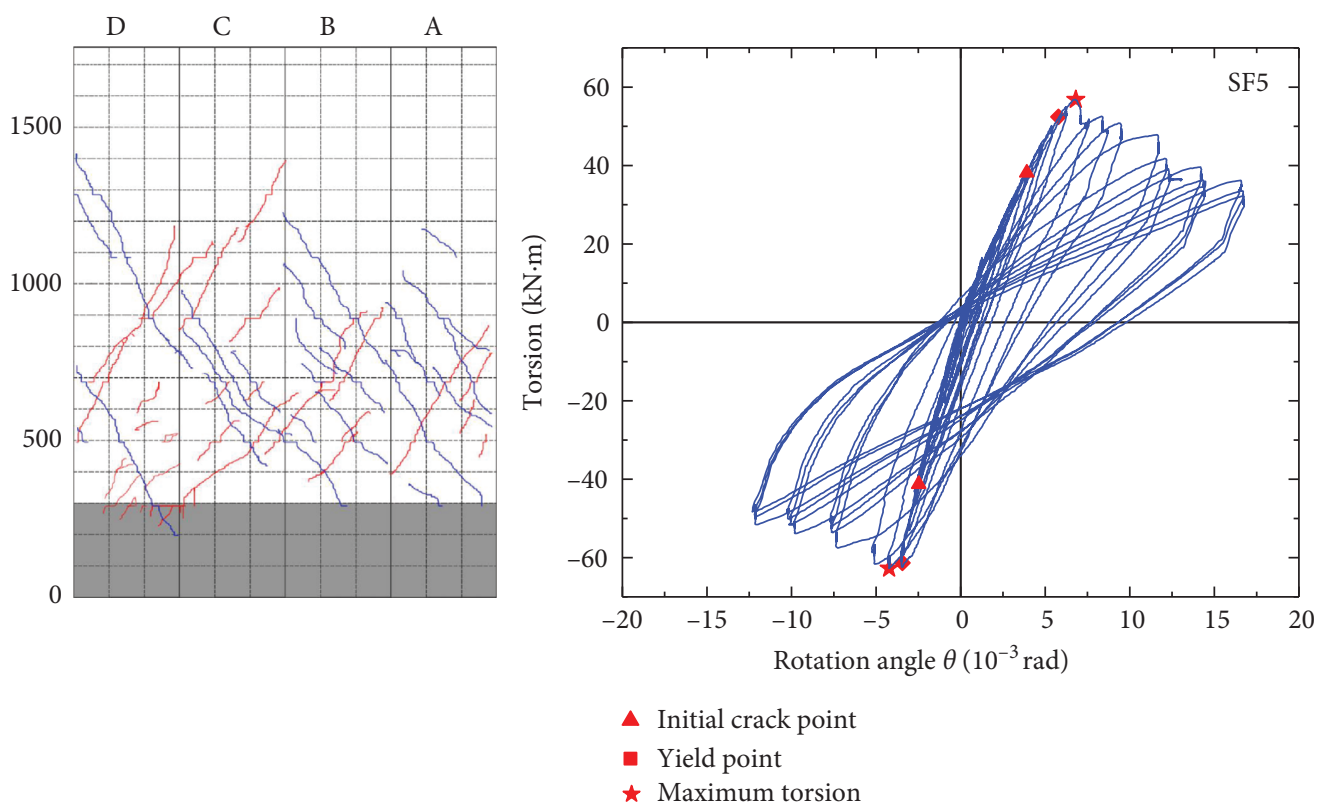

FIGURE 14: Damage and hysteresis curves of specimen SF5.

TABLE 7: Torsion and rotation angle at the critical loading stage.

\begin{tabular}{|c|c|c|c|c|c|c|c|}
\hline \multirow{2}{*}{\multicolumn{2}{|c|}{ Specimen }} & \multicolumn{2}{|c|}{ Initial crack occurred } & \multicolumn{2}{|c|}{ Yielding point } & \multicolumn{2}{|c|}{ Maximum load } \\
\hline & & $\begin{array}{l}\text { Torsion } \\
(\mathrm{kN} \cdot \mathrm{m})\end{array}$ & $\begin{array}{l}\text { Rotation angle } \\
\quad\left(10^{-3} \mathrm{rad}\right)\end{array}$ & $\begin{array}{l}\text { Torsion } \\
(\mathrm{kN} \cdot \mathrm{m})\end{array}$ & $\begin{array}{l}\text { Rotation angle } \\
\qquad\left(10^{-3} \mathrm{rad}\right)\end{array}$ & $\begin{array}{l}\text { Torsion } \\
(\mathrm{kN} \cdot \mathrm{m})\end{array}$ & $\begin{array}{l}\text { Rotation angle } \\
\quad\left(10^{-3} \mathrm{rad}\right)\end{array}$ \\
\hline & Positive & 21.09 & 1.77 & 30.06 & 3.69 & 34.58 & 7.16 \\
\hline & Negative & -21.01 & -1.65 & -42.97 & -5.50 & -55.34 & -9.33 \\
\hline & Positive & 39.22 & 3.54 & 49.82 & 4.85 & 55.84 & 5.78 \\
\hline & Negative & -40.24 & -2.94 & -53.89 & -4.59 & -59.30 & -6.08 \\
\hline & Positive & 45.70 & 4.66 & 56.23 & 5.88 & 60.15 & 6.77 \\
\hline & Negative & -44.93 & -3.36 & -59.35 & -4.64 & -62.62 & -5.05 \\
\hline & Positive & 42.54 & 4.31 & 51.43 & 5.28 & 57.76 & 6.12 \\
\hline & Negative & -44.71 & -2.76 & -55.12 & -4.87 & -62.43 & -6.33 \\
\hline & Positive & 45.24 & 4.47 & 54.97 & 5.76 & 60.75 & 6.87 \\
\hline & Negative & -47.16 & -4.41 & -54.88 & -5.24 & -59.71 & -7.10 \\
\hline & Positive & 38.15 & 3.91 & 52.41 & 5.78 & 56.83 & 6.82 \\
\hline & Negative & -41.25 & -2.48 & -61.32 & -3.45 & -62.73 & -4.23 \\
\hline
\end{tabular}

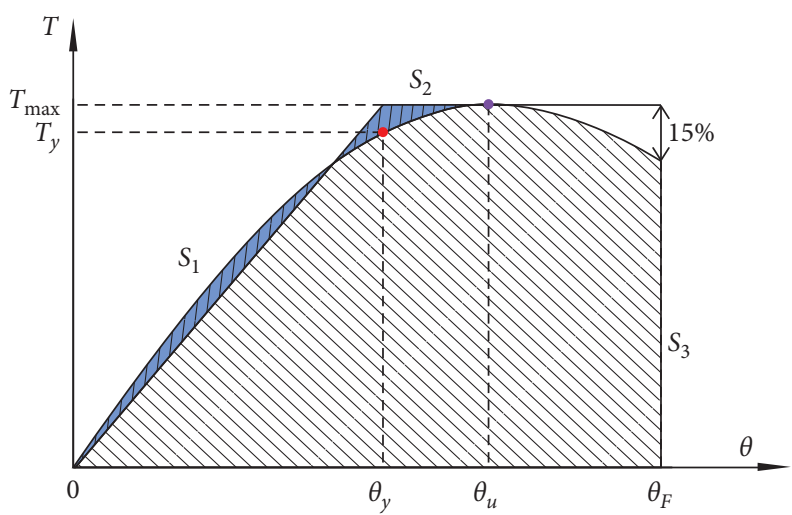

FiguRE 15: Equivalent elastic-plastic energy method $\left(S_{1}=S_{2}\right)$ and $S_{1}, S_{2}, S_{3}$ stand for the area of the regions in the torsion-rotation angle curve [42]. 
3.2. Location and Length of the Torsional Plastic Hinge. The theoretical equations for plastic hinges in various codes [37, 44-46] mainly consider bending loads. The bending loads are mainly generated by the column top shear force and $P-\delta$ effect. Plastic hinges, which develop in regions with large bending moments at the bottom of the column, are easy to predict. However, when the pier column is subjected to bending moment and torsion, especially when the deformation of the pier column is dominated by torsion, the plastic region will be extended. The location of the plastic hinge is also different from the bending-dominated deformation. As shown in Figures 8-14, the length of the crack distribution region and the severely damaged region of all specimens were noted. For specimen $\mathrm{C} 1$, a plastic hinge was located at the bottom of the pier column behaved as designed. However, for the SF series specimens, the plastic hinges were shifted away from the bottom region and up to the middle height region of the pier columns. There was no apparent damage outside the plastic hinges.

There are many damage indexes [47-49] that can be used to express the degree of surface cracking and concrete spalling of the pier after twisting. For simplicity and intuitiveness, this article used the pier cracking length as the plastic length of the pier, and the ratio was similar to the Damage Index Model [49]. From the experimental results of this study, the torsional deformation-dominated pier plastic hinge length $L_{p}$ was proposed taken as the average cracked length of these six specimens:

$$
L_{p}=0.54 L_{e},
$$

where $L_{e}$ is the height of the pier column.

The length of the severely damaged plastic hinge $L_{\mathrm{ph}}$ which has the approximate length in the range of $0.5 D_{\text {cor }}-1.5 D_{\text {cor }}[50]$ was recommended to be as follows:

$$
L_{\mathrm{ph}}=D_{\text {cor }} \text {, }
$$

where $D_{\text {cor }}$ is the core side length of the square concrete section.

3.3. Envelope Curves and Ductility. The torsional envelop curves under different torque levels and constant axial compression are shown in Figure 16. There are many similarities between the positive and negative directions of all these envelope curves that positive details are taking as examples. $\mathrm{C} 1$ and SF series specimens differ not only in peak strength but also in the way in which they deteriorate after yielding. Figure 16(a) reveals that there has a similarity in virgin stiffness of six specimens. However, the stiffness of $\mathrm{C} 1$ became nonlinear at $3.5 \times 10^{-3} \mathrm{rad}$, $34.6 \mathrm{kN} \cdot \mathrm{m}$, whereas the hysteresis envelopes of SF series specimens were linear up to $55.8-62.7 \mathrm{kN} \cdot \mathrm{m}$ with rotation angle at $\theta_{\max }=5.7-7.1 \times 10^{-3} \mathrm{rad}$, which were the rotation angles relative to their torsional strength. This showed that the torsional rigidities and peak strength of pier columns have been greatly improved when locally replaced with SFRC-FA at the bottom of pier columns, with $11-26 \%$ and $60-76 \%$, respectively. In addition, there were three obvious deterioration stages of SF series specimens: (1) a steep drop of about $15 \% T_{\max }$ following the torsional peak; (2) a moderate strength-decreasing platform between $85 \% T_{\max }$ to $75 \% T_{\max }$ and even $70 \%$ $T_{\max }$; (3) quick failure. Compared to SF series specimens, $\mathrm{C} 1$ only went through two obvious deterioration stages: a typical yielding platform under nearly double $\theta_{\max }$ between $T_{\max }$ and $85 \% T_{\max }$ and a quick failure afterward. On the other hand, few differences in envelop curves were found between SF1 and SF5 with the SFRC-FA replacement length of 300-800 $\mathrm{mm}$, meaning that increasing the replacement length had little effects on peak strength and torsional hysteresis behavior when the length exceeds the section size of members.

The limit rotation is usually defined as the corresponding rotation when the load decreases to $85 \%$ of the peak load or when the specimen is not capable of carrying the load [51], which is chosen as the rotation at the end of the deterioration platform in the envelope curves. As a result, $85 \% T_{\max }$ and $75 \% T_{\max }$, as marked in Figure 16(b), were two key points relative to the ductility in this study. When the torsion deteriorated to $D$ percent of $T_{\max }$, the ductility coefficient $\beta_{D}$ [41] is expressed by the following:

$$
\beta_{D}=\frac{\theta_{D}}{\theta_{y}}
$$

where $\theta_{y}$ is yield torsion angle of specimen; $\theta_{D}$ is rotation angle at the point where envelope curves deteriorate to $D \%$ $T_{\max }$.

Table 8 and Figure 17 illustrated that the rotation ductility of SF series specimens decreased in positive loading direction, while longer replacement length and higher stirrup ratios lead to less decrement but more obvious strength drop at $85 \% T_{\max } \sim 75 \% T_{\max }$ deterioration stage. Although SFRC-FA strengthening may lead to a $1 / 3$ ductility decrease in positive loading, the reinforcing method brings about general fortification in the negative loading condition in rotation ductility, especially in SF1. On the other hand, due to the "lock and unlock" effect [6] of hysteresis loading, the negative ductility showed 1 to 2 times increase compared to positive conditions except for $\mathrm{C} 1$, which may suffer some interference from loading setting up or unexpected bending moment caused by the $P$ $\delta$ effect.

3.4. Energy Dissipation. Figure 18 showed the equivalent viscous damping coefficient $h$, which was used to measure the energy dissipation characteristics of the SF series specimens.

$$
h=\frac{1}{2 \pi} \times \frac{S_{(\triangle \mathrm{ABC}+\triangle \mathrm{CDA})}}{S_{(\triangle \mathrm{OBE}+\triangle \mathrm{ODF})}},
$$

where $S_{(\triangle \mathrm{ABC}+\triangle \mathrm{CDA})}$ [52] equals the area enclosed by the hysteresis loop, representing the energy dissipated in the actual structure; area $S_{(\triangle \mathrm{OBE}+\triangle \mathrm{ODF})}$ is the strain energy calculated from the assumed linear elastic behavior of the same specimen. 


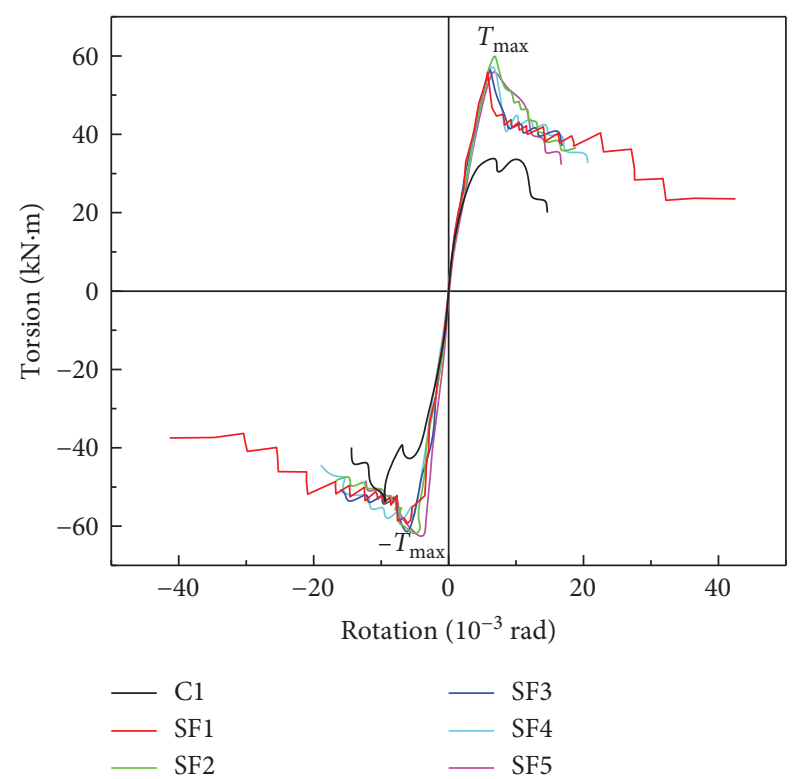

(a)

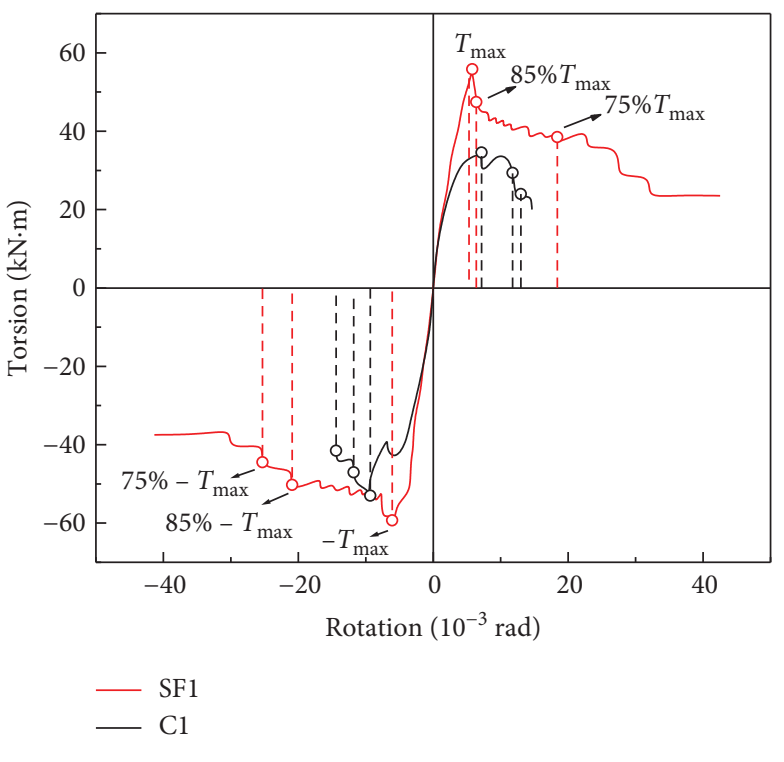

(b)

FIgURE 16: Envelop curves. (a) Envelop curves of six specimens. (b) Deterioration of C1 and SF1.

TABLE 8: Ductility coefficient of specimens.

\begin{tabular}{|c|c|c|c|c|c|c|c|c|c|}
\hline \multicolumn{2}{|c|}{ Specimen } & $\theta_{y}\left(10^{-3} \mathrm{rad}\right)$ & $T_{y}(\mathrm{kN} \cdot \mathrm{m})$ & $\theta_{85}\left(10^{-3} \mathrm{rad}\right)$ & $85 \% \pm T_{\max }(\mathrm{kN} \cdot \mathrm{m})$ & $\beta_{85}$ & $\theta_{75}\left(10^{-3} \mathrm{rad}\right)$ & $75 \% \pm T_{\max }(\mathrm{kN} \cdot \mathrm{m})$ & $\beta_{75}$ \\
\hline \multirow{2}{*}{$\mathrm{C} 1$} & Negative & -6.8 & -40.0 & -11.8 & -47.0 & 1.7 & -14.4 & -41.5 & 2.1 \\
\hline & Positive & 3.7 & 30.1 & 11.8 & 29.4 & 3.2 & 12.1 & 25.9 & 3.3 \\
\hline \multirow{2}{*}{ SF1 } & Negative & -4.6 & -53.9 & -20.9 & -50.4 & 4.6 & -25.3 & -44.5 & 5.5 \\
\hline & Positive & 4.8 & 49.8 & 6.4 & 47.5 & 1.3 & 14.1 & 41.9 & 2.9 \\
\hline \multirow{2}{*}{ SF2 } & Negative & -4.6 & -59.3 & -8.4 & -53.2 & 1.8 & -15.7 & -47.0 & 3.4 \\
\hline & Positive & 5.9 & 56.2 & 9.5 & 51.1 & 1.6 & 11.7 & 45.1 & 2.0 \\
\hline \multirow{2}{*}{ SF3 } & Negative & -4.9 & -55.1 & -15.1 & -53.1 & 3.1 & -16.0 & -46.8 & 3.3 \\
\hline & Positive & 5.3 & 51.4 & 7.2 & 49.1 & 1.4 & 10.9 & 43.3 & 2.1 \\
\hline \multirow{2}{*}{ SF4 } & Negative & -5.2 & -54.9 & -15.6 & -50.8 & 3.0 & -18.9 & -44.8 & 3.6 \\
\hline & Positive & 5.8 & 55.0 & 7.6 & 51.6 & 1.3 & 10.2 & 45.6 & 1.8 \\
\hline \multirow{2}{*}{ SF5 } & Negative & -3.4 & -61.3 & -9.8 & -53.3 & 2.8 & -13.0 & -47.0 & 3.8 \\
\hline & Positive & 5.8 & 52.4 & 11.1 & 48.3 & 1.9 & 12.0 & 42.6 & 2.1 \\
\hline
\end{tabular}

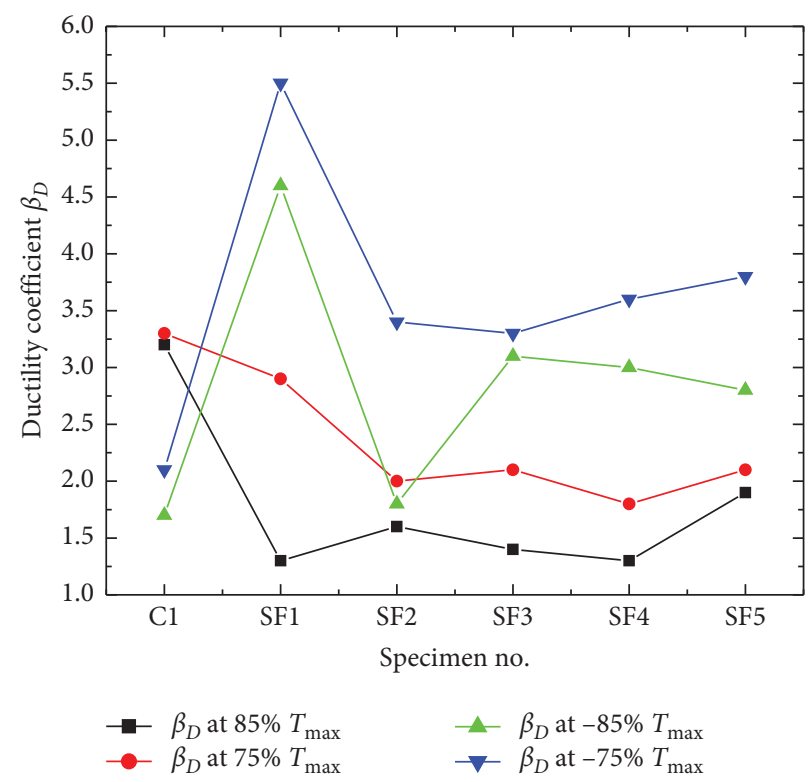

Figure 17: Ductility coefficient at $\theta_{85}$ and $\theta_{75}$ of six specimens. 


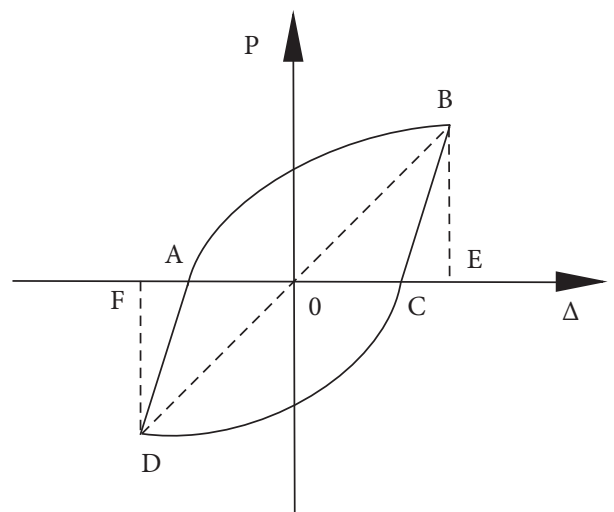

Figure 18: Loading-displacement curve.

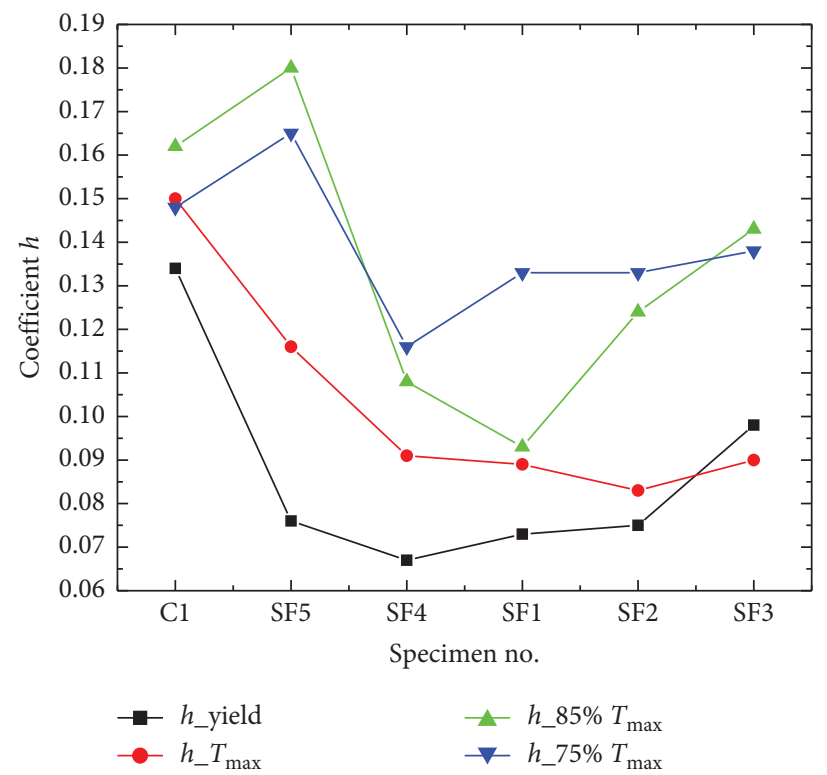

Figure 19: Coefficient $h$ at different loading stages.

As shown in Figure 19, the equivalent viscous damping coefficients were between 0.083 and 0.180 after reaching peak torsion. The energy dissipation capacity decreased slightly as the SFRC-FA replacement length increasing from 0 (C1), $300 \mathrm{~mm}$ (SF5), $500 \mathrm{~mm}$ (SF4), to $800 \mathrm{~mm}$ (SF1), which shows that a long replacement length will make it difficult to release the energy consumption capacity of SFRC-FA. Meanwhile, the energy dissipation of SF1, SF2, and SF3 specimens was not significantly different but slightly increased with the decrease of the stirrup ratio. This phenomenon may be due to the good toughness of SFRC-FA materials, and no damage occurred in the SFRC-FA replacement region until the end of loading, resulting in relatively high energy consumption due to large deformation of the specimen with a smaller stirrup ratio. On the other hand, the difference between $h_{-T \max }$ and $h_{-75 \% T \max }$ of SF series specimens was much larger than that of specimen $\mathrm{C} 1$, which may also result in better energy dissipation capacity due to the good toughness of SFRC-FA materials.

\section{Analytical Studies}

4.1. Discussion on Calculation Equation of Torsional Strength. The space truss model developed by Hsu [53, 54], which was based on the thin-walled tube theory proposed by Lampert and Collins [51], was adopted in many international design codes $[44-46,55]$. Researchers have tried to explore the relationship between torsion and axial compression based on the space truss model. Therefore, the ACI 318-08 code [56] used the space truss model shown in equation (5) to calculate the torsional strength.

$$
T=2 \frac{A_{s v} f_{y v} A_{0}}{s} \cos \alpha,
$$

where $A_{s v}$ is the area of one stirrup section; $f_{y v}$ is the yield stress of stirrup bars; $A_{0}$ is the area enclosed by the centerline of the shear flow zone; $\alpha$ is the angle of the concrete struts along the longitudinal direction.

In order to study the combined action, torsion $T$, shear $V$, bending moment $M$, and axial force $N$ were introduced in 
TABLE 9: Comparison of calculation methods of torsion bearing capacity $(\mathrm{kN} \cdot \mathrm{m})$.

\begin{tabular}{|c|c|c|c|c|c|c|c|c|}
\hline \multirow{2}{*}{ Specimens } & \multirow{2}{*}{$N / N_{0}$} & \multirow{2}{*}{$T_{0}$} & \multicolumn{6}{|c|}{ Calculated results $(\mathrm{kN} \cdot \mathrm{m})$} \\
\hline & & & $T_{1}$ & $T_{2}$ & $T_{3}$ & $T_{1} / T_{0}$ & $T_{2} / T_{0}$ & $T_{3} / T_{0}$ \\
\hline $\mathrm{C} 1$ & 0.60 & 43.38 & 38.44 & 35.73 & 52.69 & 0.89 & 0.82 & 1.21 \\
\hline SF1 & 0.60 & 57.57 & 38.44 & 35.73 & 52.69 & 0.67 & 0.62 & 0.92 \\
\hline SF2 & 0.60 & 61.39 & 38.44 & 35.73 & 52.69 & 0.63 & 0.58 & 0.86 \\
\hline SF3 & 0.60 & 60.10 & 38.44 & 35.73 & 52.69 & 0.64 & 0.59 & 0.88 \\
\hline SF4 & 0.60 & 60.23 & 38.44 & 35.73 & 52.69 & 0.64 & 0.59 & 0.87 \\
\hline SF5 & 0.60 & 59.78 & 38.44 & 35.73 & 52.69 & 0.64 & 0.60 & 0.88 \\
\hline $\mathrm{P} 1[50]$ & 0 & 72.90 & 72.51 & 50.22 & 83.70 & 0.99 & 0.69 & 1.15 \\
\hline $\mathrm{P} 2[50]$ & 0.22 & 81.60 & 72.51 & 62.39 & 95.87 & 0.89 & 0.76 & 1.17 \\
\hline C2 [57] & 0 & 82.30 & 67.60 & 45.66 & 76.10 & 0.82 & 0.55 & 0.92 \\
\hline C3 [57] & 0 & 77.20 & 67.60 & 45.66 & 76.10 & 0.88 & 0.59 & 0.99 \\
\hline C4 [57] & 0 & 95.50 & 95.60 & 64.58 & 107.63 & 1.00 & 0.68 & 1.13 \\
\hline C5 [57] & 0 & 100.70 & 95.60 & 64.58 & 107.63 & 0.95 & 0.64 & 1.07 \\
\hline C6 [57] & 0.52 & 109.70 & 87.27 & 71.88 & 111.18 & 0.80 & 0.66 & 1.01 \\
\hline C7 [57] & 0.52 & 96.30 & 67.60 & 58.59 & 89.03 & 0.70 & 0.61 & 0.92 \\
\hline R1 [58] & 1.33 & 37.93 & 24.27 & 0.64 & 27.43 & 0.72 & 35.25 & 0.93 \\
\hline R2 [58] & 1.33 & 33.46 & 24.27 & 0.73 & 27.43 & 0.82 & 35.25 & 1.05 \\
\hline R3 [58] & 1.24 & 31.31 & 23.87 & 0.76 & 27.43 & 0.88 & 34.84 & 1.11 \\
\hline R4 [58] & 1.86 & 35.73 & 24.91 & 0.70 & 27.43 & 0.77 & 35.89 & 1.00 \\
\hline R5 [58] & 1.73 & 31.38 & 24.47 & 0.78 & 27.43 & 0.87 & 35.44 & 1.13 \\
\hline R6 [58] & 2.27 & 38.34 & 25.32 & 0.66 & 27.43 & 0.72 & 36.30 & 0.95 \\
\hline R7 [58] & 2.00 & 31.00 & 24.45 & 0.79 & 27.43 & 0.88 & 35.42 & 1.14 \\
\hline R8 [58] & 2.17 & 40.35 & 27.81 & 0.69 & 32.46 & 0.80 & 40.80 & 1.01 \\
\hline R9 [58] & 1.14 & 52.10 & 35.19 & 0.68 & 44.76 & 0.86 & 53.10 & 1.02 \\
\hline \multirow{3}{*}{ Statistical analysis } & \multirow{3}{*}{\multicolumn{2}{|c|}{$\begin{array}{l}\text { Numbers of } \\
\text { specimens }\end{array}$}} & \multirow{3}{*}{23} & \multicolumn{2}{|c|}{ Average } & 0.80 & 0.67 & 1.01 \\
\hline & & & & \multirow{2}{*}{\multicolumn{2}{|c|}{$\begin{array}{l}\text { Mean square error } \\
\text { Coefficient of } \\
\text { variation }\end{array}$}} & 0.013 & 0.006 & 0.012 \\
\hline & & & & & & 0.144 & 0.112 & 0.107 \\
\hline
\end{tabular}

the thin-walled tube theory $[53,54]$. The relationships of the torsion, shear, bending moment, and axial force could be derived as follows:

$$
\frac{T^{2}}{T_{0}^{2}}+\frac{V^{2}}{V_{0}^{2}}+\frac{M}{M_{0}}-\frac{N}{N_{0}}=1,
$$

where $T_{0}, V_{0}, M_{0}, N_{0}$ mean the strength under single action of torsion, shear, bending moment, and axial compression, respectively.

Equation (6) showed that axial compression can increase the torsional strength, while shear and bending moment may reduce the torsional strength. In addition, when $V$ and $M$ were small in this study, the relationship between $T$ and $N$ can be expressed as follows:

$$
\frac{T^{2}}{T_{0}^{2}}=\frac{N}{N_{0}}+1
$$

Equation (7) demonstrated that axial compression had a positive reinforcing effect on the torsional strength of the columns.

4.2. Comparison of Calculation Methods of Torsional Bearing Capacity. The JTG 3362-2018 specification [55] noted the reinforcement effect under axial-torsional combined action. The calculation method was shown in equation (8). However, the second part of equation (8) reduced the coefficient conducted by equation (5) to 1.2, which was mainly based on regression analysis with low strength concrete (under C40). The equation was as follows:

$$
\begin{aligned}
T & =\left(0.35 f_{t}+0.07 \frac{N}{A}\right) W_{t}+1.2 \frac{A_{s v} f_{y v} A_{0}}{s} \cot \alpha, \\
W_{t} & =\frac{b^{2}(3 h-b)}{6},
\end{aligned}
$$

where $f_{t}$ is the concrete tensile strength; $W_{t}$ is the torsional plastic moment of resistance. Furthermore, the torsional reinforced effect was not taken into consideration in the Caltrans code [45], which utilizes equation (5) to calculate the torsional strength directly. As a result, a combined form of equations (5) and (8) was proposed to reflect the reinforcement effect caused by axial compression during the torsional failure in the pier columns:

$$
T=\left(0.35 f_{t}+0.07 \frac{N}{A}\right) W_{t}+2 \frac{A_{s v} f_{y v} A_{0}}{s} \cot \alpha .
$$

As shown in Table 9, $T_{0}, T_{1}, T_{2}$, and $T_{3}$ represent the experimental result and the calculated results by equations (5), (8), and (10), respectively. The calculated results $T_{2}$ of this study and other studies in the literature by equation (8) were most conservative for the torsional bearing capacity, which was mainly due to the coefficient reduction of equation (5). Moreover, the calculated results $T_{1}$ by equation (5) fitted well in the case that $N=0$, while it led to $15 \sim 35 \%$ smaller results under axial compression, indicating that it 
was necessary to consider the cracking torsional strength of core concrete and reinforced effect from axial compression. In general, the calculated results $T_{3}$ by equation (10) were in good agreement with the test results.

\section{Conclusions}

The seismic behavior tests and theoretical studies on the pier columns of SFRC-FA replacing conventional concrete in the potential plastic hinges were carried out subject to torsion combined with axial compression. The major conclusions drawn from the above studies are as follows:

(1) The evolution process of the rotation angle and the crack patterns of the test specimens indicated that the torsional seismic failure mode of the pier columns was obviously dependent on the SFRC-FA replacement length. With the increase of the SFRCFA replacement length at the bottom of the pier column, the plastic hinge was shifted up to the conventional concrete region in the middle of the height of the pier column. Although the plastic hinge length of SF series specimens was basically the same as that of the conventional concrete specimen, it improved the torsional bearing capacity and ductility of the pier column.

(2) In the tests of the SF1 3 pier columns, the change of the stirrup ratio $(0.343-0.686 \%)$ had little effect on the torsional bearing capacity, ductility, cracking pattern, energy dissipation, and other seismic behaviors, which indicated that the application of SFRC-FA material in the potential plastic hinge region could reduce the stirrup ratio.

(3) Based on the space truss model, a new equation for calculating the torsion bearing capacity was proposed, taken into account the effect of axial force and the application of SFRC-FA. Compared with the equations proposed by various international codes, the equation proposed herein did not underestimate the torsion bearing capacity, whose coefficient of variation was better.

(4) In total, the experimental results proved that the application of SFRC-FA in the potential plastic hinge region changed the failure mode and improved the torsional bearing capacity of the pier column. Certainly, further rigorous studies are wanted to understand the interactions between the SFRC-FA and the conventional concrete and their effect on the seismic behaviors of the composite pier columns. In addition, testing SFRC-FA pier columns under combined cyclic bending-torsion loads with larger torsion-bending ratios may be a focus for further research.

\section{Data Availability}

The raw/processed data required to reproduce these findings cannot be shared at this time as the data are also part of an ongoing study. The datasets generated and/or analyzed during the current study are available from the corresponding author on reasonable request.

\section{Conflicts of Interest}

The authors declare that they have no conflicts of interest.

\section{Acknowledgments}

This study was supported by the National Natural Science Foundation of China (51578495) and Zhejiang Provincial Natural Science Foundation of China (LY16E080002). The authors appreciate the great assistance of Xiao-Hua JI and $\mathrm{Yu}$ Peng in the execution of experiments.

\section{References}

[1] M. J. N. Priestley and R. Park, "Strength and ductility of concrete bridge columns under seismic loading," ACI Structural Journal, vol. 84, no. 1, pp. 61-67, 1987.

[2] J. B. Mander, S. M. Waheed, M. T. A. Chaudhary, and S. S. Chen, "Seismic performance of shear-critical reinforced concrete bridge piers," Technical report, State University of New York at Buffalo, Buffalo, NY, USA, 1993.

[3] A. M. Abdel-Ghaffar and L. I. Rubin, "Torsional earthquake response of suspension bridges," Journal of engineering mechanics, vol. 110, no. 10, pp. 1467-1484, 1984.

[4] J. D. Deng, Z. G. Ma, A. R. Liu, and S. Cao, "Seismic performance of reinforced concrete bridge columns subjected to combined stresses of compression, bending, shear, and torsion," Journal of Bridge Engineering, vol. 22, no. 11, Article ID 01017099, 2017.

[5] P. Tirasit and K. Kawashima, "Effect of nonlinear seismic torsion on the performance of skewed bridge piers," Journal of Earthquake Engineering, vol. 12, no. 6, pp. 980-998, 2008.

[6] S. Prakash, Q. Li, and A. Belarbi, "Behavior of circular and square reinforced concrete bridge columns under combined loading including torsion," ACI Structural Journal, vol. 109, no. 3, pp. 317-327, 2012.

[7] A. E. Abdelnaby, T. M. Frankie, A. S. Elnashai et al., "Numerical and hybrid analysis of a curved bridge and methods of numerical model calibration," Engineering Structures, vol. 70, pp. 234-245, 2014.

[8] T. G. Mondal and S. S. Prakash, "Nonlinear finite-element analysis of RC bridge columns under torsion with and without axial compression," Journal of Bridge Engineering, vol. 21, no. 2, Article ID 04015037, 2016.

[9] Z.-B. Pi, M. Su, Y.-Y. Peng, Y.-H. Wang, W. Luo, and Y.-S. Lan, "Seismic behaviour of concrete-filled steel tubular columns with internal $\mathrm{H}$-section steel under pure torsion and compression-torsion loads," Engineering Structures, vol. 216, Article ID 110761, 2020.

[10] Y.-H. Wang and X.-H. Zhou, "Non-linear torsion behaviour of concrete filled steel tube columns," Materials and Structures, vol. 49, no. 12, pp. 5227-5241, 2016.

[11] Y. H. Wang, J. G. Nie, and J. S. Fan, "Theoretical model and investigation of concrete filled steel tube columns under axial force-torsion combined action," Thin-Walled Structures, vol. 69, pp. 1-9, 2013.

[12] J.-g. Nie, Y.-h. Wang, and J.-s. Fan, "Experimental study on seismic behavior of concrete filled steel tube columns under pure torsion and compression-torsion cyclic load," Journal of Constructional Steel Research, vol. 79, pp. 115-126, 2012. 
[13] W. C. Liao, K. Y. Liu, and C. C. Yeh, "Behaviors of new RC bridge columns made of highly flowable strain-hardening fiber-reinforced concrete (HF-SHFRC) under cyclic loads," Journal of Testing and Evaluation, vol. 47, no. 3, pp. 17771792, 2019.

[14] A. Reggia, A. Morbi, and G. A. Plizzari, "Experimental study of a reinforced concrete bridge pier strengthened with HPFRC jacketing," Engineering Structures, vol. 210, Article ID 110355, 2020.

[15] Y. Pang and L. Li, "Seismic collapse assessment of bridge piers constructed with steel fibers reinforced concrete," PLoS One, vol. 13, no. 7, Article ID e0200072, 2018.

[16] F. Germano, G. Tiberti, and G. Plizzari, "Experimental behavior of SFRC columns under uniaxial and biaxial cyclic loads," Composites Part B: Engineering, vol. 85, pp. 76-92, 2016.

[17] Y. Jia, R. Zhao, F. Li et al., "Seismic performance of bridge piers constructed with PP-ECC at potential plastic hinge regions," Materials, vol. 13, p. 1856, 2020.

[18] A. Mohebbi, M. S. Saiidi, and A. M. Itani, "Shake table studies and analysis of a precast two-column bent with advanced materials and pocket connections," Journal of Bridge Engineering, vol. 23, no. 7, Article ID 04018046, 2018.

[19] A. Mohebbi, M. S. Saiidi, and A. M. Itani, "Shake table studies and analysis of a PT-UHPC bridge column with pocket connection," Journal of Structure Engineering, vol. 144, no. 4, Article ID 04018021, 2018.

[20] W. L. Qiu, C. S. Kao, C. H. Kou, and J. L. Tasi, “Experimental study of seismic performances of RC bridge columns with CFST column embedded inside," Journal of Marine Science and Technology, vol. 23, no. 2, pp. 212-219, 2015.

[21] M. F. Javed, N. H. R. Sulong, S. A. Memon, S. K. U. Rehman, and N. B. Khan, "FE modelling of the flexural behaviour of square and rectangular steel tubes filled with normal and high strength concrete," Thin-Walled Structures, vol. 119, pp. 470-481, 2017.

[22] M. F. Javed, F. Farooq, S. A. Memon et al., "New prediction model for the ultimate axial capacity of concrete-filled steel tubes: an evolutionary approach," Crystals, vol. 10, no. 741, 2020.

[23] H. Ju, D. H. Lee, J.-H. Hwang, J.-W. Kang, K. S. Kim, and Y.-H. Oh, "Torsional behavior model of steel-fiber-reinforced concrete members modifying fixed-angle softened-truss model," Composites Part B: Engineering, vol. 45, no. 1, pp. 215-231, 2013.

[24] Y.-y. Zhang, K. A. Harries, and W.-c. Yuan, "Experimental and numerical investigation of the seismic performance of hollow rectangular bridge piers constructed with and without steel fiber reinforced concrete," Engineering Structures, vol. 48, pp. 255-265, 2013.

[25] Y. Y. Zhang, H. Y. Wei, W. C. Yuan, and W. Hu, "Seismic performance of SFRC piers under reversed cyclic loading," Applied Mechanics and Materials, vol. 178-181, pp. 22282235, 2012.

[26] Y. Zhang, J. Fan, and W. Fan, "Seismic fragility analysis of concrete bridge piers reinforced by steel fibers," Advances in Structural Engineering, vol. 19, no. 5, pp. 837-848, 2016.

[27] Y. Zhang and D. Dias-da-Costa, "Seismic vulnerability of multi-span continuous girder bridges with steel fibre reinforced concrete columns," Engineering Structures, vol. 150, pp. 451-464, 2017.

[28] S. M. F. Mahmood, A. Agarwal, S. J. Foster, and H. Valipour, "Flexural performance of steel fibre reinforced concrete beams designed for moment redistribution," Engineering Structures, vol. 177, pp. 695-706, 2018.

[29] K. S. Kim, D. H. Lee, J.-H. Hwang, and D. A. Kuchma, "Shear behavior model for steel fiber-reinforced concrete members without transverse reinforcements," Composites Part B: Engineering, vol. 43, no. 5, pp. 2324-2334, 2012.

[30] A. Fatih, H. Tefaruk, and A. Kamura, "Effects of steel fiber addition on mechanical properties of concrete and RC beams," Construction and Building Materials, vol. 21, no. 3, pp. 654-661, 2007.

[31] V. C. Li, "On engineered cementitious composites (ECC): a review of the material and its applications," Journal of Advanced Concrete Technology, vol. 1, no. 3, pp. 215-230, 2003.

[32] S. Qudah and M. Maalej, "Application of engineered cementitious composites (ECC) in interior beam-column connections for enhanced seismic resistance," Engineering Structures, vol. 69, pp. 235-245, 2014.

[33] J. Y. Wang, W. Q. Ma, C. L. Wan et al., "Experimental study on seismic performance of PE fiber cementitious composite frame joints," World Earthquake Engineering, vol. 33, no. 4, pp. 180-186, 2017, in Chinese.

[34] F. Yuan, L. Chen, M. Chen, and K. Xu, "Behaviour of hybrid steel and FRP-reinforced concrete-ECC composite columns under reversed cyclic loading," Sensors, vol. 18, no. 12, p. 4231, 2018.

[35] F. Hosseini, B. Gencturk, H. Aryan, and G. Cadaval, "Seismic behavior of 3-D ECC beam-column connections subjected to bidirectional bending and torsion," Engineering Structures, vol. 172, pp. 751-763, 2018.

[36] G. J. Parra-Montesinos, "High-performance fiber-reinforced cement composites: an alternative for seismic design of structures," ACI Structural Journal, vol. 102, no. 5, pp. 668$675,2005$.

[37] JTG/T B02-01-2008, Guidelines for Seismic Design of Highway Bridges, China Communication Press, Beijing, China, 2008, in Chinese.

[38] J. Y. Wang, W. Q. Ma, Z. H. Hu et al., "Effect of PE fiber content on mechanical behavior of cementitious composite," Journal of Zhejiang University (Engineering Science), vol. 51, no. 11, pp. 2130-2135, 2017, in Chinese.

[39] Y. Li, R. D. Chen, and J. Y. Wang, "Mix proportion design of steel fiber fine aggregate concrete based on orthogonal test method," Concrete, vol. 12, pp. 90-93, 2020, in Chinese.

[40] Chinese National Standard, Common Portland Cement, GB175-2007, China Communications Press, Beijing, China, 2007.

[41] S. Chen, W. Peng, and W. Yan, "Experimental study on steel reinforced concrete columns subjected to combined bendingtorsion cyclic loading," The Structural Design of Tall and Special Buildings, vol. 27, no. 11, Article ID e1479, 2018.

[42] J. Wang, C. Wan, Q. Zeng, L. Shen, M. A. Malik, and D. Yan, "Effect of eccentricity on retrofitting efficiency of basalt textile reinforced concrete on partially damaged masonry columns," Composite Structures, vol. 232, Article ID 111585, 2020.

[43] R. Park, "State of the art report ductility evaluation from laboratory and analytical testing," in Proceedings of 9th World Conference on Earthquake Engineering, pp. 605-616, Tokyo, Japan, 1988.

[44] JRA-2002, Design Specifications for Highway Bridges, Part V: Seismic Design, Japan Road Association, Tokyo, Japan, 2002.

[45] Caltrans-2010, Seismic Design Criteria, California Department of Transportation, Sacramento, CA, USA, 2010. 
[46] Eurocode8-2005, Design Provisions for Earthquake Resistance of Structures-Part 2: Bridges, Committee European de Normalization, Brussels, Belgium, 2005.

[47] A. Ghobarah, "Performance-based design in earthquake engineering: state of development," Engineering Structures, vol. 23, no. 8, pp. 878-884, 2001.

[48] S.-H. Jeong and A. S. Elnashai, "New three-dimensional damage index for RC buildings with planar irregularities," Journal of Structural Engineering, vol. 132, no. 9, pp. 14821490, 2006.

[49] S. S. Prakash and A. Belarbi, "Towards damage-based design approach for RC bridge columns under combined loadings using damage index models," Journal of Earthquake Engineering, vol. 14, no. 3, pp. 363-389, 2010.

[50] P. Tirasit and K. Kawashima, "Seismic performance of square reinforced concrete columns under combined cyclic flexural and torsional loadings," Journal of Earthquake Engineering, vol. 11, no. 3, pp. 425-452, 2007.

[51] P. Lampert and M. P. Collins, "Torsion, bending, and confusion-an attempt to establish the facts," Journal of ACI, vol. 69 , no. 8, pp. 500-504, 1972.

[52] C. A. Blandon and M. J. N. Priestley, "Equivalent viscous damping equations for direct displacement based design," Journal of Earthquake Engineering, vol. 9, no. sup2, pp. 257-278, 2005.

[53] T. T. C. Hsu, Torsion of Reinforced Concrete, Van Nostrand Reinhold, Inc., New York, NY, USA, 1984.

[54] T. T. C. Hsu, "Torsion of structural concrete: behavior of reinforced concrete rectangular members," Torsion of Structural Concrete, ACI SP-18, pp. 261-306, American Concrete Institute, Indianapolis, IN, USA, 1968.

[55] JTG 3362-2018, Specifications for Design of Highway Reinforced Concrete and Prestressed Concrete Bridges and Culverts, Ministry of Transport of China, Beijing, China, 2018, in Chinese.

[56] ACI 318-08, Building Code Requirements for Structural Concrete and Commentary, American Concrete Institute, Indianapolis, IN, USA, 2008.

[57] B. Jakobsen, E. Hjorth-Hansen, and I. Holamd, "Cyclic torsion tests of concrete box columns," Journal of Structural Engineering, vol. 110, no. 4, pp. 803-822, 1984.

[58] Q. Li and A. Belarbi, "Damage assessment of square RC bridge columns subjected to torsion combined with axial compression, flexure, and shear," KSCE Journal of Civil Engineering, vol. 17, no. 3, pp. 530-539, 2013. 